Article

\title{
American State Ballot Initiatives and Income Inequality
}

\author{
Joshua J. Dyck ${ }^{1, *}$, Wesley Hussey ${ }^{2}$ and Edward L. Lascher, Jr. ${ }^{3}$ \\ ${ }^{1}$ Political Science Department, University of Massachusetts Lowell, Lowell, MA 01854, USA; E-Mail: joshua_dyck@uml.edu \\ 2 Political Science Department, California State University, Sacramento, CA 95819, USA; E-Mail: whussey@csus.edu \\ ${ }^{3}$ Department of Public Policy \& Administration, California State University, Sacramento, CA 95819, USA; \\ E-Mail: tedl@csus.edu \\ * Corresponding author
}

Submitted: 11 December 2018 | Accepted: 8 February 2019 | Published: 27 June 2019

\begin{abstract}
Some have argued that the ballot initiative process prevalent in many American states might lower inequality. We contend this is improbable based on what is known about whether expansion of democracy leads to redistribution, the attitudes of citizens, and the characteristics of the initiative process. Nevertheless, the proposition needs testing. We examine three types of evidence. First, we analyze the content and passage of all post-World War II initiatives going to voters in California, a state that makes heavy use of ballot propositions. Second, we model institutional factors influencing differences in inequality at the state-level from 1976-2014 to test the aggregate-level effect of ballot initiatives on income inequality. Third, we use individual level data to evaluate the claim that frequent initiative use makes lower income people happier because it helps to reduce inequality. Our analyses consistently indicate that the ballot initiative process fails to reduce income inequality.
\end{abstract}

\section{Keywords}

direct democracy; life satisfaction; income inequality; state ballot initiatives; redistribution

\section{Issue}

This article is part of the issue "The Politics, Promise and Peril of Direct Democracy", edited by Todd Donovan (Western Washington University, USA).

(C) 2019 by the authors; licensee Cogitatio (Lisbon, Portugal). This article is licensed under a Creative Commons Attribution 4.0 International License (CC BY).

\section{Introduction}

Might direct democracy in the American states be a means for reducing income inequality? Some have hoped this would be the case. Indeed, people commonly tell the story that the initiative process was a Progressive Era created tool allowing the public to bypass state legislatures corrupted by large moneyed interests and catering to the wealthy (see Eule, 1990). Presumably the initiative was a means of correcting the imbalance, which logically might include redistributing income (some advocates also favored measures directly aimed at doing so such as the progressive income tax). Careful historical analysis has not been kind to the presumption that the initiative process, eventually established in 24 of 50 states, was important to fighting corporate power or advancing a Progressive economic agenda (see especially Ellis, 2002). Nevertheless, modern day Progressive organizations such as the Ballot Initiative Strategy Center (The Ballot Initiative Strategy Center, n.d.) still argue that direct democracy can be a key tool in advancing the interests of the many relative to the wealthy. Moreover, one recent academic book (Franko \& Witko, 2018) argues that in the current era of greater public concern within the American public about growing inequality, the initiative process encourages adoption of redistributive policies. Additionally, another recent academic study (Radcliff \& Shufeldt, 2016) claims to offer evidence that greater use of ballot initiatives enhances the subjective well-being of lower income citizens. The authors contend this is likely because of redistributive policies under the initiative process. 
Accordingly, it is worth considering whether use of state ballot initiatives is associated with income redistribution. We address the topic using three different methods and a variety of data. First, we examine the substance and voting results of ballot measures in the entire post-World War II era for California, a state which especially uses ballot initiatives. We consider how frequently people face redistributive ballot measures, their explicit aims, and how often they pass. Second, we examine data on income distribution across the American states, focusing on whether use of the ballot initiative affects such distribution controlling for a variety of other factors. Third, we reassess survey data reported to show that greater use of initiatives leads to more life satisfaction among low income individuals, potentially traceable to redistributive policy.

For reasons explained in the following section, we began this study skeptical of the idea that the initiative process encourages redistribution. We found our skepticism justified. None of the empirical approaches we undertook supported the idea that direct democracy in the American states promotes redistribution and/or works to effectively reduce income inequality.

\section{Theory and Expectations}

The logic behind an argument that ballot initiatives may promote redistribution centers on how they might move policy closer to the median income voter, with the presumption that representative institutions may be tilted toward the preferences of higher status, more organized citizens. Radcliff and Shufeldt (2016) make this explicit:

[S]ince direct democracy is a majoritarian institution, the outcomes may be relatively more responsive to the preferences of low SES [socioeconomic status] individuals than representative institutions. Put differently, direct democracy might have the strongest impact on those of lower SES precisely because their voices are so feebly and inconsistently heard in representative institutions...such that initiatives may offer a more level playing field. (2016, pp. 1411-1412)

This argument implies that extending the ability of ordinary citizens to make democratic choices will allow low and middle income voters to unite to promote redistribution against the interests of a wealthy minority; Shapiro (2002) refers to this as the "redistributive thesis."

A more subtle argument suggests that direct democracy promotes redistribution only during periods when the median voter expresses greater concern about income inequality, such as has occurred in the United
States in recent decades. Franko and Witko (2018) make this case in their recent study of responses to economic inequality in the American states: "As government fails to address inequality, the initiative is being used to craft policy intended to slow or roll back growing inequality" (p. 102). Their argument (2018, pp. 141-142, 168) is explicitly grounded in the presumption that the academic literature establishes that direct democracy, as a majoritarian institution, moves policy closer to the desires of the median voter, per research such as that conducted by Matsusaka (2004). Yet this claim is controversial, and more recent studies have cast doubt on the conclusion that the American ballot initiative process operates in the manner suggested by Matsusaka (Lax \& Phillips, 2009; Monogan, Gray, \& Lowery, 2009).

Moreover, based on reconsideration of their own data, we find reasons to be skeptical about the claims about redistribution made by Franko and Witko (2018). Their strongest evidence pertains to enactment of minimum wage increases; they provide compelling findings that initiatives are associated with state increases in the minimum wage in recent years, controlling for other variables. Yet they acknowledge that the minimum wage is a very simple policy and uncommonly easy to explain to voters. We would add that it also does not require voters to commit government resources or raise tax revenues. When Franko and Witko examine state adoption of an Earned Income Tax Credit (EITC), a more complex policy that does require commitment of government revenues, they fail to find support for a connection between initiative use and redistribution in their multivariate analysis. Indeed, we note that of the 15 early adopters of the EITC which established such a policy between 1986 and 2000 (see Franko \& Witko, 2018, p. 158), eleven were noninitiative states. ${ }^{1}$ There is also the question of whether minimum wage increases have lasting effects that would meaningfully decrease inequality. In 2006, for instance, six states passed initiatives to increase their minimum wage. Yet, in the same election, the Democrats took control of the US Congress and between 2008 and 2010 raised the federal minimum wage from $\$ 5.15$ an hour to $\$ 7.25 .^{2}$

There are several broader problems with the line of argument that the state initiative process encourages redistribution. First, there is a lack of general evidence in a wide variety of contexts for the redistributive thesis. Indeed, Shapiro writes:

This is one thesis that history has soundly refuted. Although there have been redistributive eras in capitalist democracies since the advent of a universal franchise, there has been no systematic relationship

\footnotetext{
${ }^{1}$ The non-initiative state early EITC adopters, in order of adoption, included Rhode Island (1986), Maryland (1987), Vermont (1988), lowa (1989), Wisconsin (1989), Minnesota (1991), New York (1994), Kansas (1998), Indiana (1999), Illinois (2000), and New Jersey (2000). The initiative state early adopters included Massachusetts (1997), Oregon (1997), Colorado (1999), and Maine (2000). We count Illinois as a non-initiative state in the present context since that state's highly restrictive process only allows initiatives for structural changes in state government.

2 In 2010, the first year of the $\$ 7.25$ minimum wage implementation, only two of the six states that passed minimum wage increases in 2006 had minimum wages greater than the new federal minimum: Ohio at $\$ 7.30$ an hour and Nevada at $\$ 7.55$ an hour. Arizona, Colorado, Missouri, and Montana were all at or below the federal rate upon implementation in 2010.
} 
between democracy and downward redistribution. (2002, p. 118)

Second, the idea that self-interest will necessarily push middle- and low-income initiative voters to unite is theoretically suspect, as suggested in the "median voter" literature applied to direct democracy. On strictly selfinterested economic grounds, middle class voters may be better off uniting with the wealthy, especially if the ballot measure is framed in such a way as to provide middle class voters some net benefits, even if providing upper class voters a much larger share (see Feld, Fischer, \& Kirchgässner, 2010; Harms \& Zink, 2003). This tendency is exacerbated if, as is commonly the case, low income voters are known to participate less frequently (Verba, Schlozman, \& Brady,1995). The widely cited Sears and Citrin (1982) study of the battle over the influential Proposition 13 property tax reduction measure in California argues for precisely this self-interested alignment of middle- and upper-class voters. Indeed, one study suggested that towns in Sweden with direct democracy spent $40-60 \%$ less on public welfare; the authors hypothesized that this is because direct democracy governments are more prone to elite capture (Hinnerich \& Pettersson-Lidbom, 2014). Another suggests that lowincome citizens often bear the brunt of the service decreases that result from high-income citizens voting for tax decreases (Sances, 2018).

Third, as a matter of political psychology it is questionable whether lower- and middle-class voters necessarily want to redistribute income in the manner suggested by the redistributive thesis (see especially Shapiro, 2002). Much literature suggests that a great many Americans, even those with lower incomes, believe a market distribution of income is fair and may be reluctant to try to tamper with that distribution. Moreover, people even at the low end of the income spectrum may embrace the "American dream" and believe that they will someday join the upper ranks. They will therefore be reluctant to support imposing higher taxes on the wealthy to support enhanced social programs that reach the middle class and poor. Similar sentiments are among the factors that drive widespread opposition to estate taxes, even though they are paid by relatively few wealthy individuals (Graetz \& Shapiro, 2011). Middleand upper-class citizens may also look down on lower class citizens for "poor choices," and be disinclined to support measures mainly targeted at helping them (e.g., Gilens, 1999). Additionally, policy making elites insulated from electoral pressure may be more sympathetic to redistribution than average voters, suggesting that a move toward direct democracy could reduce inclination to pursue redistributive policy (Sances, 2016).

Finally, some of the very factors scholars have found associated with the failure of Congress and other national institutions to address rising income inequality also characterize the ballot initiative process in the United States. In an exhaustive review, Bonica, McCarty,
Poole and Rosenthal (2013) identify a number of such factors, including low voting rates among the poor as well as sharply rising costs of campaigns that are increasingly financed by high income voters. Yet these factors are not just characteristic of candidate races for federal offices; they are also true of state ballot initiative contests. As far back as 1984, Magleby produced systematic evidence that low income voters were significantly underrepresented in voting on California ballot measures, and this was even more the case than in voting on candidate races. Additionally, simply getting an initiative measure on the ballot requires substantial resources, and usually the backing of wealthy donors to bankroll signature gathering campaigns, which recently have averaged between \$1 and \$10 per signature depending on the state and continue to rise (Dyck \& Lascher, 2019). It is common for initiative contests to generate more than $\$ 1$ million in spending, with most of the monies coming from wealthy individuals and organizations.

In short, prior literature suggests that we should not expect state ballot initiatives to reduce income inequality. Nevertheless, some have argued otherwise, and one important recent study (Franko \& Witko, 2018) contends that direct democracy is a tool for addressing high and rising inequality in the contemporary era. Additional systematic empirical study is therefore needed.

\section{Data, Methods, and Results}

We seek to test whether ballot initiatives reduce income inequality in the American states and subject that hypothesis to rigorous empirical testing. We use three distinct approaches. First, we offer a qualitative of study of which initiatives do and do not pass. If ballot initiates lower inequality, we would expect to find the passage of a significant number of economically substantial measures that could be expected to decrease inequality. Second, we analyze aggregate economic outcomes from 1976-2014 in the American states and consider whether ballot initiative usage appears to reduce inequality. Not only does this enable us to look beyond a single state, but it allows us to consider the possible indirect policy effects of the initiative process that are sometimes claimed. We also consider the effect of the minimum wage on income inequality, and in particular, of minimum wage ballot initiatives on income inequality. Finally, we test whether the frequency of ballot initiatives leads to an increase in life satisfaction among individuals with the lowest incomes, those with the most to gain from economic redistribution.

\subsection{Redistributive Ballot Measures in California}

California has been a leader in the use of direct democracy and is second behind Oregon with the number of total initiatives appearing on the statewide ballot since their introduction to the state in 1911 (Ballotpedia: The encyclopedia of American politics, n.d.-a). The "initiative industry" that coordinates signature gathering and orga- 
nizes campaigns came to prominence in the Golden State. Academic and non-academic books have been written about initiative contests in California (e.g., Broder, 2001; Chávez, 1998; Sears \& Citrin, 1982). If we are going to see if direct democracy has any direct effect on economic redistribution, California is a good place to start.

We use two main sources of data. The main one is the California Ballot Measures Database at UC Hastings Law Library (UC Hastings, CA Ballot Measures). This online archive includes the full text of individual ballot propositions and mailed ballot pamphlets. The second is the National Conference of State Legislatures (NCSL) online Statewide Ballot Measures Database. We use the Hastings archive to determine the content and intent of ballot measures and the NCSL archive to determine voting results. Starting in 2012, NCSL's Statewide Ballot Measures Database only includes preliminary vote totals. To get the official, final certified voting results, we switched to Ballotpedia, which gathers their data from the California Secretary of State (Ballotpedia: The encyclopedia of American politics. (n.d.-b).

California voters considered $838^{3}$ propositions from November 1946 through November 2018, the period we focus upon for this article. ${ }^{4}$ While almost all of these measures appeared on the primary or general election ballots in even numbered years, some occurred at more unusual times due to special statewide elections. Of the total 838, we concentrated on 279 that can be classified as originating with citizens rather than the state legislature, i.e., initiative constitutional amendments, initiative statutes, and popular/veto referendums to overturn acts of the legislature. The vast majority of such citizen-sponsored measures were initiative statutes and initiative constitutional amendments.

We developed our own scheme for determining if citizen measures were redistributive and classified them as either "liberal" (i.e., pro-redistribution) or "conservative" (i.e., anti-redistributive). We looked at two main criteria: whether the measure would expand the role and size of government or the amount of government revenue, and whether the measure generally aimed at strengthening the power of workers, worker organizations or consumers in direct economic terms vis-à-vis employers. If a measure increased taxes, increased other sorts of revenue, significantly expanded government programs, expanded employee rights, strengthened labor unions, or imposed price caps or mandatory price rollbacks on consumers, we labeled it as liberal. If instead it cut taxes, eliminated or shrank government programs, restricted governmental revenue, strengthened the hand of employers, weakened labor unions, or removed price ceilings, we labeled it as conservative.

Our coding scheme implies that many measures commonly labeled by others as "conservative" or "liberal" would not meet our definitions for purposes of this project, because they were not primarily economically redistributive. Thus, we would not classify an initiative to legalize marijuana as liberal or a measure to strengthen criminal penalties as conservative.

We also ignored a number of measures that were minor or technical in impact. Voters commonly were asked to decide issues such as whether adding earthquake retrofits could avoid property tax reassessment and consequently a somewhat higher tax bill. Such measures did not make it on our redistribution list. In contrast, we classify as conservative a 1984 initiative statute that would have drastically cut public welfare payments; the measure failed, garnering only $37 \%$ of the vote in the general election.

Table 1 provides a summary of the aggregate results for citizen-sponsored measures (initiative constitutional amendments, initiative statutes, initiative bonds, and referenda) we classified as either conservative or liberal in economic redistributionist terms from 1946 onward. We discern several key points. First, less than half of all petition measures $(46 \%$, or 129 out of 279$)$ can be classified as economically redistributionist. Looking at just liberal measures, that number falls below $20 \%$. So, compared to citizen originated measures in general, liberal economic measures rarely qualify for the ballot. Second, most of these redistributive measures fail, with voters rejecting $69 \%$ of liberal measures and $67 \%$ of conservative measures. Non-economic measures only failed $54 \%$ of the time. Finally, liberal measures collectively did worse with voters than conservative measures, averaging a smaller percentage of the vote. Both groups received on average fewer yes votes than non-redistributive measures.

While there were almost twice as many liberal measures on the ballot than conservative measures, a striking feature of most successful liberal measures is their limited redistributionist scope. Before 1992 there are no measures establishing or even expanding broad taxes, making existing taxes more progressive, establishing or expanding broad social programs, increasing the minimum wage, or strengthening collective bargaining. The only tax increase passed was on smoking, and that reflected more so an emerging social consensus about reducing the harmful health effects of tobacco use than citizens engaging in redistribution activity (Cummings \& Proctor, 2014).

Moreover, many of the more substantially liberal measures were defeated and not subsequently enacted, at the ballot or through the legislature. For example, Democratic Governor Jerry Brown and other prominent liberals backed Proposition 11 on the 1980 primary ballot that would have established a $10 \%$ oil surtax, using the campaign slogan, "tax big oil." The funds would have been used for increased bus and transportation

\footnotetext{
${ }^{3}$ Six propositions were removed by the courts after they were already placed on the ballot. These are not included.

${ }^{4}$ Note that some of the ballot pamphlets in the pre-War era had minimal information compared to more modern pamphlets, making analysis of measures difficult. For example, the 1920 general election pamphlet contained for each measure a short, legalistic summary followed by the proposed statutory language without any explanation of implications. These were in turn followed by arguments for and against the measures, sometimes without identifying the affiliation of the person writing the argument.
} 
Table 1. Results for citizen-sponsored measures, 1946-present.

\begin{tabular}{|c|c|c|c|}
\hline & Conservative & Liberal & Non-Redistributive \\
\hline Passed & $\begin{array}{l}16 \\
(33 \%)\end{array}$ & $\begin{array}{l}25 \\
(31 \%)\end{array}$ & $\begin{array}{l}71 \\
(46 \%)\end{array}$ \\
\hline Failed & $\begin{array}{l}32 \\
(67 \%)\end{array}$ & $\begin{array}{l}56 \\
(69 \%)\end{array}$ & $\begin{array}{l}82 \\
(54 \%)\end{array}$ \\
\hline Total & $\begin{array}{l}48 \\
(100 \%)\end{array}$ & $\begin{array}{l}81 \\
(100 \%)\end{array}$ & $\begin{array}{l}153 \\
(100 \%)\end{array}$ \\
\hline Average Yes (unweighted) & $46.8 \%$ & $42.8 \%$ & $49.1 \%$ \\
\hline
\end{tabular}

services and to develop alternative transportation fuels. Only $44 \%$ of the electorate voted in favor of the measure. Voters rejected an oil severance tax again in 2006 by a similar margin, and California remains the only major oilproducing state without a statewide severance tax.

It was not until the mid-1990s that substantially liberal measures started doing better at the polls. Californians passed a small increase in the minimum wage, expanded after-school programs, and passed several citizen-initiated bonds. They also lowered the legislative requirement to pass the annual budget, while also approving several tax increases. Nevertheless, only a third of all liberal initiatives have passed since 1992, compared to a $29 \%$ passage rate from 1946 to 1990 .

For every successful tax increase or liberal ballot measure passed since the 1990s, many more liberal measures failed. Voters killed an increase in the gas tax, the aforementioned oil severance tax, a statewide parcel tax for schools, higher taxes for universal preschools, cigarette taxes, and a 1996 initiative that would have increased taxes on the wealthy. Californians voted against the public financing of campaigns in 2000 and 2006, and in 2018 they voted down a measure that would have allowed strong rent control at the local level. California might have become a more liberal state, but its voters are still quite cautious when it comes to liberal economic ballot measures.

By contrast, conservative measures passed by voters have sustained far greater impact. The clearest example is Proposition 13, passed in 1978, which drastically lowered property taxes, restricted the ability of representative institutions to raise other types of taxes, restructured the relationship between state and local governments, and launched the populist tax revolt movement worldwide. Other major conservative measures enacted include: a 1950 initiative requiring approval of the local electorate before any public funded low-income housing project can be built; a cap on total state government spending passed in 1979; and two similar measures in 1986 and 1996 requiring voter approval for any tax increase at the local level.

In short, it is difficult to look at the overall results from 1946 through 2018 and fail to conclude that conservatives collectively scored more successes than liberals on redistribution issues decided at the ballot box. Con- servative measures not only succeed slightly more often, but the successful scope of conservative initiatives seems far greater as well. Even in contemporary liberal California, during the period in which Franko and Witko (2018) claim states have been responding to perceived increased economic inequality, conservatives still find some avenues to restrict redistribution, and most liberal measures still fail.

\subsection{Aggregate Analysis of Income Inequality in the States}

Based on analysis of the substance and success of California ballot measures, there is little reason to think the ballot initiative process in the Golden State directly reduced income inequality. Nevertheless, it is possible that California is an outlier in this respect and/or that the impact of the ballot initiative is mostly indirect. That is, perhaps the threat of a ballot initiative encourages lawmakers to pass redistributive legislation aimed at reducing inequality to head off more extreme versions that might be approved by votes. In other contexts, some scholars have argued that the threat of the initiative constrains legislative behavior in such a manner (e.g., Gerber, 1996), albeit without systematic empirical evidence of how frequently this occurs (see Dyck \& Lascher, 2019). We are skeptical that the threat of the initiative would necessarily push lawmakers toward enacting redistributive legislation favoring the less well-off (e.g., passage of an income tax surcharge to fund programs targeted at low income voters) rather than the opposite (e.g., passage of property tax relief tilted toward high income citizens). Yet more empirical evidence is needed.

Fortunately, we can build on a recent study to test the claim that cross-state differences in use of the initiative process are associated with differences in income inequality. Bucci (2018a) developed a data set allowing her to compare income inequality across all 50 states for the period 1976 to 2014, giving her a 39 year cross-sectional time-series dataset. This allowed for a contrast of the commonly used Gini index of household income for each state in each year. Her primary purpose was to assess the impact of labor unionization on income inequality across states, controlling for a wide variety of other variables. She did not consider direct democracy mechanisms; we 
added such information to the data set. If the ballot initiative process indeed helped to reduce income inequality, we would expect to see that the Gini index would be lower in states making greater use of the initiative process (controlling for other variables).

Here, we model both market inequality and posttransfer inequality as a function of the ballot initiative process. We follow the modeling approach suggested by Kelly and Witko (2012), who use an error correction model. Put in simple terms, we operationalize the dependent variable at time period $t$ as the change from $t-1$ to $t$. Each independent variable then includes a change variable and a lag variable when appropriate; if either of these is significant, we can say that the variable exerts a significant effect on income inequality.

The model includes controls for union density ${ }^{5}$, policy liberalism, gross state product, the percentage of the state economy that is based in manufacturing, the percentage of the population that is nonwhite, and the unemployment rate. ${ }^{6}$

We also introduce two simple measures of the initiative process. One is the dummy variable of whether or not the state has the ballot initiative. This should give us the average effect comparing initiative to non-initiative states and has been frequently used in aggregate studies of the initiative (e.g., Boehmke, 2005; Matsusaka, 2004). Additionally, we include a measure for initiative density, using the average number of initiatives on the ballot in the state from 1900 to the present year, lagged one year. This captures the large state level variance in initiative use. Finally, we introduce two ways to capture the effect of the minimum wage on income inequality. First, we include a variable that measures the value of the state minimum wage in excess of the federal minimum wage. This measure is used to capture the independent effect of state minimum wage laws insofar as they exceed the minimum wage standards set by the federal government. This is included as a control in all the models that use a general measure of the ballot initiative to predict income inequality. Second, we explicitly model in Table 2 the effect of state minimum wage ballot initiatives passage on income inequality. ${ }^{7}$ The models are all estimated using generalized least squares with random effects and clustered state standard errors.

The results conform mostly to expectations. Market inequality, as measured by the Gini index, is lower in states with higher union density, less policy liberalism, a minimum wage that is higher than the federal standard, and those that experience lower levels of unemployment. Post-transfer inequality, also measured by the Gini index, is lower in states with higher union density, lower unemployment, a lower gross state product, and when there is a smaller non-white population. Notably, in all four models in Table 2, for both income inequality in the labor market (market inequality) and income inequality that is calculated after accounting for redistributive government programs (post-transfer inequality), both measures of the ballot initiative (a simple dummy $(0,1)$ for the existence of the initiative and a measure of initiative density) have no effect on either form of income inequality. Also, of particular interest is that minimum wage policies appear to reduce income inequality in the labor market, as we might expect, but when we account for income inequality after redistribution has taken place, there is no effect for minimum wage policies on income inequality (Models 2-3 and 2-4).

In Table 3, we take the test of the effect of minimum wage policies on income inequality further, considering the effect of minimum wage ballot initiatives on both market inequality and post-transfer inequality. Between 1976 and 2014, 11 states raised their minimum wages via ballot initiatives, with the majority of these increases coming in $2006 .{ }^{8}$ Using this measure in lieu of both the minimum wage measure and the ballot initiative measure in Table 3 produces null effects in predicting both market inequality and post-transfer inequality. Therefore, while the literature may have firmly established a connection between ballot initiatives and minimum wage policies (Franko \& Witko, 2018), the empirical connection between the minimum wage and income inequality remains tenuous. As we would expect, minimum wage increases in states that are above the federal minimum reduce inequality in the labor market. However, the effects of the reductions are subsumed by the social safety net when we measure inequality after accounting for government redistribution. Furthermore, we cannot attribute this reduction to policies passed via the ballot initiative. And this is the case even though there is reason to think that minimum wages are easier to enact by the initiative process than other redistributive measures, as we indicated previously.

Overall, we see no evidence in either model that the presence or usage of direct democracy has any impact on income inequality. Consistent with our observation that redistribution in California is a rare ballot initiative event, we now see with a comprehensive quantitative aggregate analysis of all 50 states over nearly a 40-year period that direct democracy is not associated with lower levels of state level income inequality. This analysis accounts for both direct and indirect effects, and also considers the special case of whether the ballot initiative has reduced income inequality via the minimum wage.

\footnotetext{
${ }^{5}$ This was the main focus of Bucci's (2018a) study and despite the addition of additional variables and a different modeling approach, we found this variable very robust to additional variables and model choice.

6 The data here come from Bucci (2018b). Exceptions to this are: unemployment data are from Klarner (2015); Minimum wage data are from the United States Department of Labor (n.d.); and ballot initiative data are from the authors' personal database.

${ }^{7}$ A state-year is coded 1 if a state passed a minimum wage initiative in the previous year and then is coded 1 for every subsequent year. All other state-years are coded as 0 .

${ }^{8}$ The states are Arizona (2006), California (1996), Colorado (2006), Florida (2004), Missouri (2006), Montana (2006), Nevada (2004 \& 2006), Ohio (2006), Oregon (1996 \& 2002), South Dakota (2014), and Washington (1988 \& 1998). Data collected from the NCSL (n.d.).
} 
Table 2. Initiatives and income inequality, 1976-2014.

\begin{tabular}{|c|c|c|c|c|c|c|c|c|}
\hline \multirow[b]{3}{*}{ Variables } & \multicolumn{4}{|c|}{$\Delta$ Market Gini Coefficient } & \multicolumn{4}{|c|}{$\Delta$ Post-Transfer Gini Coefficient } \\
\hline & \multicolumn{2}{|c|}{ Model 2-1 } & \multicolumn{2}{|c|}{ Model 2-2 } & \multicolumn{2}{|c|}{ Model 2-3 } & \multicolumn{2}{|c|}{ Model 2-4 } \\
\hline & $\beta$ & $S E$ & $B$ & $S E$ & $\beta$ & $S E$ & $\beta$ & $S E$ \\
\hline Market Gini $(t-1)$ & -0.1643 & $0.0193^{* * *}$ & -0.1645 & $0.0198 * * *$ & - & - & - & - \\
\hline Post-transfer Gini $(t-1)$ & - & - & - & - & -0.2195 & $0.0218^{* * *}$ & -0.2190 & $0.0214^{* * *}$ \\
\hline$\Delta$ Union Density & -0.0534 & 0.0331 & -0.0533 & 0.0329 & -0.0592 & $0.0264^{*}$ & -0.0598 & $0.0263^{*}$ \\
\hline Union Density $(t-1)$ & -0.0474 & $0.0130 * * *$ & -0.0478 & $0.0123^{* * *}$ & -0.0506 & $0.0129 * * *$ & -0.0520 & $0.0125^{* * *}$ \\
\hline$\Delta$ Policy Liberalism & -0.0107 & 0.0227 & -0.0093 & 0.0226 & -0.0033 & 0.0212 & -0.0025 & 0.0211 \\
\hline Policy Liberalism $_{(t-1)}$ & 0.0091 & $0.0044^{*}$ & 0.0096 & $0.0041^{*}$ & 0.0072 & 0.0045 & 0.0081 & $0.0041^{*}$ \\
\hline$\Delta$ Gross State Product & -0.0249 & 0.0214 & -0.0272 & 0.0217 & 0.0019 & 0.0184 & 0.0027 & 0.0190 \\
\hline $\begin{array}{l}\text { Gross State } \\
\text { Product }(t-1)\end{array}$ & 0.0054 & 0.0028 & 0.0056 & $0.0027^{*}$ & 0.0093 & $0.0036 * *$ & 0.0094 & $0.0033 * *$ \\
\hline$\Delta \%$ Manufacturing & 0.0273 & 0.0326 & 0.0287 & 0.0328 & 0.0024 & 0.0294 & 0.0038 & 0.0294 \\
\hline$\%$ Manufacturing $(t-1)$ & 0.0029 & 0.0072 & 0.0036 & 0.0065 & -0.0072 & 0.0061 & -0.0057 & 0.0057 \\
\hline$\Delta \%$ Pop Nonwhite & 0.0237 & 0.0307 & 0.0241 & 0.0306 & 0.0257 & 0.0253 & 0.0271 & 0.0250 \\
\hline$\%$ Pop Nonwhite $(t-1)$ & 0.0056 & 0.0041 & 0.0060 & 0.0037 & 0.0099 & $0.0044^{*}$ & 0.0104 & $0.0042^{*}$ \\
\hline $\begin{array}{l}\Delta \text { State Min. Wage } \\
\text { Above Fed. }\end{array}$ & -0.0038 & 0.0021 & -0.0037 & 0.0021 & 0.0021 & 0.0017 & 0.0021 & 0.0017 \\
\hline $\begin{array}{l}\text { State Min. Wage } \\
\text { Above Fed. }{ }_{(t-1)}\end{array}$ & -0.0029 & $0.0009 * *$ & -0.0029 & $0.0010 * *$ & 0.0001 & 0.0008 & 0.0001 & 0.0009 \\
\hline$\Delta \%$ Unemployment & 0.0950 & $0.0371 *$ & 0.0950 & $0.0375^{*}$ & 0.0570 & 0.0314 & 0.0578 & 0.0317 \\
\hline Unemployment $(t-1)$ & 0.1484 & $0.0218^{* * *}$ & 0.1477 & $0.0220 * * *$ & 0.0736 & $0.0192^{* * *}$ & 0.0737 & $0.0196 * * *$ \\
\hline Initiative $(0,1)_{(t-1)}$ & -0.0004 & 0.0012 & - & - & -0.0008 & 0.0012 & - & - \\
\hline$\Delta$ Initiative Density & - & - & -0.0272 & 0.0191 & - & - & -0.0026 & 0.0192 \\
\hline Initiative Density $(t-1)$ & - & - & 0.0001 & 0.0006 & - & - & -0.0005 & 0.0006 \\
\hline Constant & 0.0770 & $0.0099 * * *$ & 0.0768 & $0.0103^{* * *}$ & 0.0949 & $0.0098^{* * *}$ & 0.0942 & $0.0097^{* * *}$ \\
\hline $\mathrm{R}^{2}$ (within) & \multicolumn{2}{|c|}{.164} & \multicolumn{2}{|c|}{.163} & \multicolumn{2}{|c|}{.177} & \multicolumn{2}{|c|}{.176} \\
\hline $\mathrm{R}^{2}$ (between) & \multicolumn{2}{|c|}{.030} & \multicolumn{2}{|c|}{.030} & \multicolumn{2}{|c|}{.003} & \multicolumn{2}{|c|}{.002} \\
\hline $\mathrm{R}^{2}$ (overall) & \multicolumn{2}{|c|}{.110} & \multicolumn{2}{|c|}{.110} & \multicolumn{2}{|c|}{.111} & \multicolumn{2}{|c|}{.111} \\
\hline $\mathrm{N}$ & \multicolumn{2}{|c|}{1900} & \multicolumn{2}{|c|}{1900} & \multicolumn{2}{|c|}{1900} & \multicolumn{2}{|c|}{1900} \\
\hline
\end{tabular}

Notes: models are GLS error correction models calculated with random effects; standard errors have been clustered by state. ${ }^{* * *} \mathrm{p}<.001$, $* * p<.01, * p<.05$.

\subsection{Direct Democracy, Redistribution, and Life Satisfaction}

Our final empirical investigation focuses on the individual level. Recently, Radcliff and Shufeldt (2016) advanced the argument that ballot initiatives might increase the subjective well-being of low-income individuals. They argue that this is because both the intrinsic and instrumental effects of ballot initiatives on citizens will especially be felt by low-income citizens. By intrinsic benefits, they refer to the oft-cited secondary effects of direct democracy (c.f. Smith \& Tolbert, 2004), whereby citizens are thought to acquire the positive normative attributes of more en- gaged democratic citizens. By instrumental benefits, they refer to the policies passed at the ballot box. Radcliff and Shufeldt (2016, pp. 1417-1418) connect the idea directly to redistribution and ballot initiatives in concluding:

While direct democracy involves little costs to anyone, it provides the bulk of its rewards to low- and middle- income individuals. Direct democracy, at least in the context of the American States, may then work in a logic consistent with the simple majoritarian interpretation of democracy...creating as it does an environment in which persons of modest means win politically. 
Table 3. Minimum wage initiatives and income inequality, 1976-2014.

\begin{tabular}{|c|c|c|c|c|}
\hline \multirow[b]{3}{*}{ Variables } & \multicolumn{2}{|c|}{$\Delta$ Market Gini Coefficient } & \multicolumn{2}{|c|}{$\Delta$ Post-Transfer Gini Coefficient } \\
\hline & \multicolumn{2}{|c|}{ Model 3-1 } & \multicolumn{2}{|c|}{ Model 3-2 } \\
\hline & $B$ & $S E$ & $\beta$ & $S E$ \\
\hline Market Gini $(t-1)$ & -0.1684 & $0.0201 * * *$ & - & - \\
\hline Post-transfer Gini ${ }_{(t-1)}$ & - & - & -0.2163 & $0.0217 * * *$ \\
\hline$\Delta$ Union Density & -0.0556 & 0.0332 & -0.0605 & $0.0265^{*}$ \\
\hline Union Density $_{(t-1)}$ & -0.0455 & $0.0130 * * *$ & -0.0511 & $0.0127 * * *$ \\
\hline$\Delta$ Policy Liberalism & -0.0124 & 0.0226 & -0.0013 & 0.0211 \\
\hline Policy Liberalism $(t-1)$ & 0.0061 & 0.0037 & 0.0081 & 0.0042 \\
\hline$\Delta$ Gross State Product & -0.0284 & 0.0202 & 0.0062 & 0.0169 \\
\hline Gross State Product $_{(t-1)}$ & 0.0054 & 0.0030 & 0.0087 & $0.0036^{*}$ \\
\hline$\Delta \%$ Manufacturing & 0.0180 & 0.0322 & 0.0064 & 0.0295 \\
\hline$\%_{\text {Manufacturing }}^{(t-1)}$ & 0.0057 & 0.0070 & -0.0051 & 0.0053 \\
\hline$\Delta \%$ Pop Nonwhite & 0.0221 & 0.0316 & 0.0275 & 0.0252 \\
\hline$\%$ Pop Nonwhite $(t-1)$ & 0.0059 & 0.0037 & 0.0108 & $0.0041^{* *}$ \\
\hline$\Delta \%$ Unemployment & 0.0802 & 0.0356 & 0.0522 & 0.0301 \\
\hline Unemployment $(t-1)$ & 0.1481 & $0.0233^{* * *}$ & 0.0677 & $0.0193 * * *$ \\
\hline Min. Wage Initiative $(0,1)(t-1)$ & -0.0008 & 0.0015 & 0.0004 & 0.0015 \\
\hline Constant & 0.0775 & $0.0106 * * *$ & 0.0931 & $0.0098 * * *$ \\
\hline $\mathrm{R}^{2}$ (within) & & & & \\
\hline $\mathrm{R}^{2}$ (between) & & & & \\
\hline $\mathrm{R}^{2}$ (overall) & & & & \\
\hline $\mathrm{N}$ & & & & \\
\hline
\end{tabular}

Notes: models are GLS error correction models calculated with random effects; standard errors have been clustered by state. ${ }^{* * *} \mathrm{p}<.001$, $* * p<.01, * p<.05$.

Thus far, the results of our aggregate analysis indicate that there is little reason to suspect that there would be any empirical support for the instrumental benefits argument. Furthermore, recent studies have largely undermined the evidence for the positive secondary effects of the state ballot initiative process and even supported a negative relationship between initiative use and trust in government (for a summary of recent studies and presentation of additional evidence see Dyck \& Lascher, 2019). We therefore find no reason to hypothesize that more ballot initiatives lead to greater life satisfaction, and no reason to suspect that this effect is stronger among those at lower income levels. Yet we note that one widely cited study indicated that direct democracy led to greater life satisfaction in Switzerland (Frey \& Stutzer, 2000), though this finding has been challenged on empirical grounds (Dorn, Fischer, Kirchgässner, \& Sousa-Poza, 2008).

Nevertheless, we reexamine the data from the DDB Life Style Survey popularized by Putnam (2000) and used in Radcliff and Shufeldt (2016). This dataset includes over 45,000 cases from Americans in the 48 lower contiguous states surveyed from 1985 through 1998 . We leave most of the details of our replication and extension of their results to a supplementary appendix. However, here we offer two broad points. First, we think that the models presented by Radcliff and Shufeldt (2016) can be significantly improved. Second, their results did not appropriately consider the substantive meaning of the interaction effects, which we demonstrate to be of negligible significance. We begin on this latter point by recovering the predicted values from Radcliff and Shufeldt's (2016) Table $1 \mathrm{a}$, which we were able to replicate given the generosity of the authors in sharing their data and coding.

In Figures 1 and 2, we present the predicted values from this model at the minimum and maximum values of income. In Figure 1, we see that those at higher incomes enjoy a higher life satisfaction when living in noninitiative states, but as initiative usage increases, this gap appears to close. Yet this is .07 difference on a 6-point scale (4.00 to 4.07 ), or a maximum difference of $1 \%$. In Figure 2, we see the full value of the life satisfaction measure plotted on the $Y$ axis as a 6-point Likert scale. It is apparent that (1) there is no discernible substantive relationship between ballot initiative usage and life satis- 


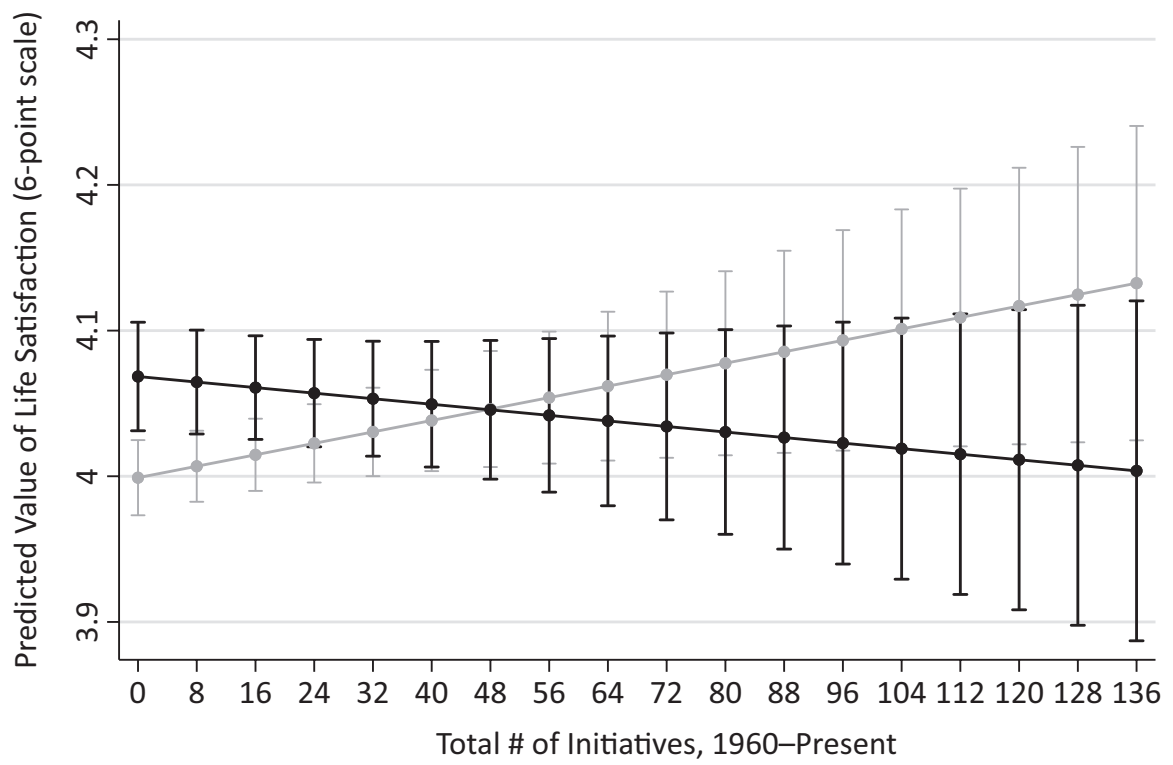

$\longrightarrow$ under $\$ 10,000 \longrightarrow \$ 100,000$ or more

Figure 1. Interaction of initiative and income, from Radcliff and Shufeldt (2016), Table 1a.

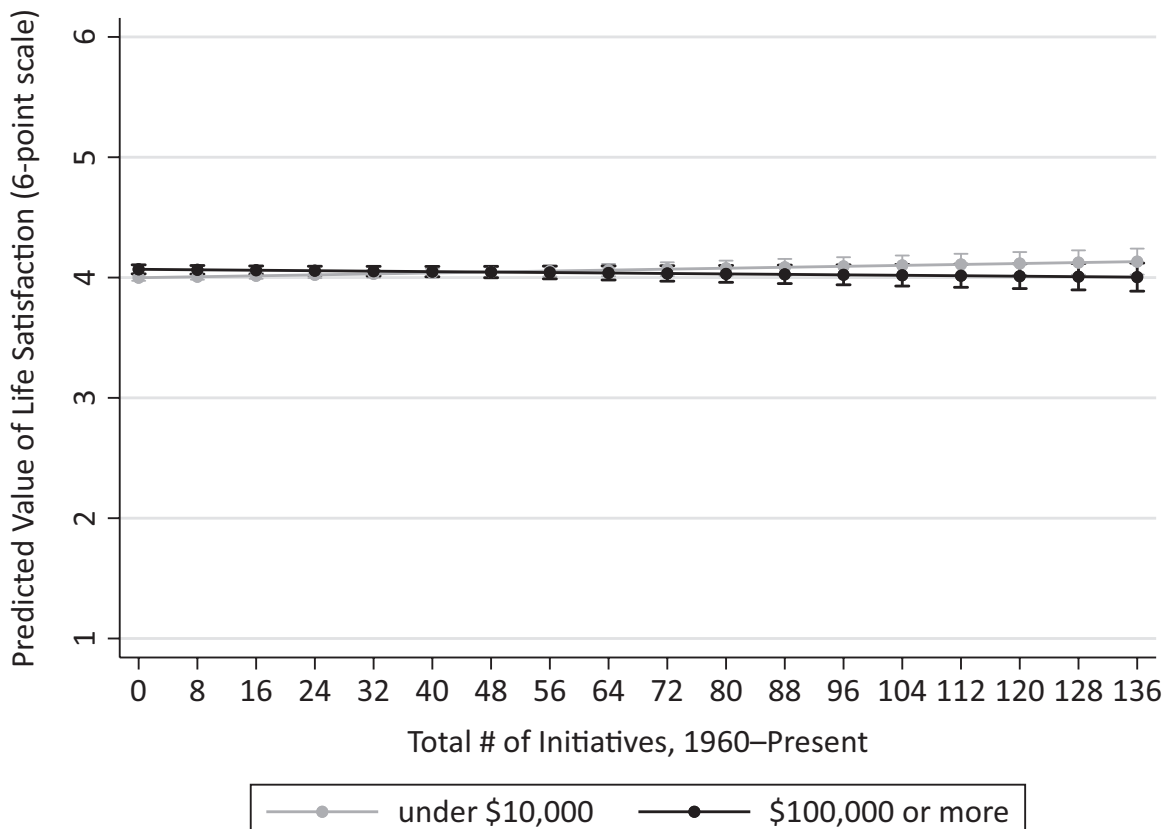

Figure 2. Figure 1, with the Y-axis rescaled to represent the full range of plausible values.

faction for those at high incomes or low incomes, and (2) this relationship is in no meaningful way mediated by income. In other words, these lines depict the same negligible effect. The dataset is large $(45,000$ cases) and so we are seeing statistically significant results on this interaction which are not substantively interesting.

Furthermore, as we detail in the supplementary appendix, there are two problems with the Radcliff and Shufeldt (2016) initiative measures. First, we uncovered a significant data coding error for the initiative measure in our replication. Second, the structure of the measure builds in an unnecessary time dimension by pivoting the measure of usage at 1960 and adding it up to the survey year (instead of using an average). As ballot initiative usage increases over time, this means this measure will always increase for initiative states and will build a time trend within states across years into the dataset. When we correct these and other problems, the statistically (but not substantively) significant interaction effect that Radcliff and Shufeldt (2016) reported between initiatives and income dissipates. In Table 4, we demonstrate what happens to the main models when the initiative variable is corrected. The interaction effect produces a null effect. 
Table 4. Initiatives, income and life satisfaction, DDB life style survey, 1985-1998.

\begin{tabular}{|c|c|c|c|c|c|c|c|c|c|c|c|c|}
\hline & \multicolumn{2}{|c|}{$\begin{array}{c}\text { Table 1, Model a } \\
\text { Random State } \\
\text { Effects (a) }\end{array}$} & \multicolumn{2}{|c|}{$\begin{array}{l}\text { Replication with } \\
\text { initiative variable } \\
\text { corrected (b) }\end{array}$} & \multicolumn{2}{|c|}{$\begin{array}{l}\text { Replication with } \\
\text { initiative variable } \\
\text { average (c) }\end{array}$} & \multicolumn{2}{|c|}{$\begin{array}{l}\text { Table 1, Model b } \\
\text { State Clustered Std. } \\
\text { Errors with year \& } \\
\text { region dummies (d) }\end{array}$} & \multicolumn{2}{|c|}{$\begin{array}{c}\text { Replication with } \\
\text { initiative variable } \\
\text { corrected (e) }\end{array}$} & \multicolumn{2}{|c|}{$\begin{array}{c}\text { Replication with } \\
\text { initiative variable } \\
\text { average (f) }\end{array}$} \\
\hline & Coef & SE & Coef & SE & Coef & SE & Coef & SE & Coef & SE & Coef & SE \\
\hline Total Initiatives & .109 & $.005^{* *}$ & 0.104 & $0.043 * *$ & & & .060 & $.029 * *$ & 0.001 & 0.043 & & \\
\hline Avg Initiatives & - & - & - & - & 0.030 & $0.014 * *$ & - & - & - & - & -0.001 & 0.013 \\
\hline Individual Income & .005 & $.002 * * *$ & 0.005 & $0.002 * *$ & 0.005 & $0.002 * *$ & .005 & $.002 * * *$ & 0.005 & $0.002 * * *$ & 0.005 & $0.002 * * *$ \\
\hline Ins X Income & -.010 & $.005^{* *}$ & -0.006 & 0.005 & -0.002 & 0.002 & -.010 & $.000 * * *$ & -0.005 & $0.003^{+}$ & -0.002 & 0.001 \\
\hline \multicolumn{13}{|l|}{ State Level Vars } \\
\hline State Population & -.000 & $.000 * *$ & 0.000 & $0.000 * * *$ & 0.000 & $0.000 * * *$ & -.000 & $.000 * *$ & 0.000 & $0.000^{+}$ & 0.000 & $0.000^{+}$ \\
\hline State Income (PC) & .000 & $.000 * *$ & 0.000 & $0.000 * *$ & 0.000 & $0.000 * *$ & .000 & .000 & 0.000 & 0.000 & 0.000 & 0.000 \\
\hline Racial Diversity & .154 & $.076 * *$ & 0.155 & $0.076 * *$ & 0.160 & $0.076 * *$ & .178 & $.115^{* *}$ & 0.172 & 0.117 & 0.171 & 0.118 \\
\hline Social Capital & .016 & .015 & 0.008 & 0.016 & 0.010 & 0.016 & .030 & .024 & 0.029 & 0.024 & 0.029 & 0.024 \\
\hline \multicolumn{13}{|l|}{ Ind'I Level Vars } \\
\hline Financial Satisfaction & .394 & $.004^{* * *}$ & 0.394 & $0.004 * * *$ & 0.394 & $0.004 * * *$ & .394 & $.005^{* * *}$ & 0.394 & $0.005^{* * *}$ & 0.394 & $0.005^{* * *}$ \\
\hline Education & -.019 & $.005^{* * *}$ & -0.019 & $0.005^{* * *}$ & -0.019 & $0.005^{* * *}$ & -.019 & $.005^{* * *}$ & -0.019 & $0.005^{* * *}$ & -0.019 & $0.005^{* * *}$ \\
\hline Unemployed $(0,1)$ & -.313 & $.035^{* * *}$ & -0.314 & $0.035^{* * *}$ & -0.314 & $0.035 * * *$ & -.311 & $.043 * * *$ & -0.311 & $0.043^{* * *}$ & -0.311 & $0.043^{* * *}$ \\
\hline Sex & .088 & $.012 * * *$ & 0.087 & $0.012 * * *$ & 0.087 & $0.012 * * *$ & .088 & $.013 * * *$ & 0.088 & $0.013^{* * *}$ & 0.087 & $0.013 * * *$ \\
\hline Children & -.109 & $.013^{* * *}$ & -0.108 & $0.013^{* * *}$ & -0.108 & $0.013 * * *$ & -.109 & $.015^{* * *}$ & -0.109 & $0.015^{* * *}$ & -0.109 & $0.015^{* * *}$ \\
\hline Black & -.200 & $.025 * * *$ & -0.200 & $0.025^{* * *}$ & -0.200 & $0.025^{* * *}$ & -.198 & $.031 * * *$ & -0.198 & $0.031 * * *$ & -0.198 & $0.031 * * *$ \\
\hline Race-Other & .002 & .028 & -0.001 & 0.028 & 0.000 & 0.028 & .003 & .016 & 0.003 & 0.016 & 0.003 & 0.016 \\
\hline Age & -.042 & $.002 * * *$ & -0.042 & $0.002 * * *$ & -0.042 & $0.002 * * *$ & -.042 & $.003 * * *$ & -0.042 & $0.003 * * *$ & -0.042 & $0.003 * * *$ \\
\hline $\mathrm{Age}^{2}$ & .000 & $.000 * * *$ & 0.000 & $0.000 * * *$ & 0.000 & $0.000 * * *$ & .000 & $.000 * * *$ & 0.000 & $0.000 * * *$ & 0.000 & $0.000 * * *$ \\
\hline Widowed & .217 & $.031 * * *$ & 0.217 & $0.031 * * *$ & 0.217 & $0.031 * * *$ & .215 & $.038 * * *$ & 0.215 & $0.038 * * *$ & 0.215 & $0.038 * * *$ \\
\hline Divorced & .051 & $.027^{* * *}$ & 0.050 & $0.027^{+}$ & 0.050 & $0.027^{+}$ & .047 & .040 & 0.047 & 0.040 & 0.047 & 0.040 \\
\hline Married & .293 & $.021 * * *$ & 0.293 & $0.021 * * *$ & 0.292 & $0.021 * * *$ & .291 & $.029 * * *$ & 0.291 & $0.029 * * *$ & 0.291 & $0.029 * * *$ \\
\hline Church Attendance & .030 & $.002 * * *$ & 0.030 & $0.002 * * *$ & 0.030 & $0.002 * * *$ & .030 & $.003 * * *$ & 0.030 & $0.003 * * *$ & 0.030 & $0.003 * * *$ \\
\hline Social Trust & .106 & $.005^{* * *}$ & 0.106 & $0.005^{* * *}$ & 0.106 & $0.005^{* * *}$ & .105 & $.004 * * *$ & 0.105 & $0.004^{* * *}$ & 0.105 & $0.004 * * *$ \\
\hline Health of $R$ & .148 & $.004^{* * *}$ & 0.148 & $0.004^{* * *}$ & 0.148 & $0.004 * * *$ & .148 & $.005^{* * *}$ & 0.148 & $0.005^{* * *}$ & 0.148 & $0.005^{* * *}$ \\
\hline Year & -.001 & $.002 * * *$ & -0.001 & 0.002 & -0.001 & 0.002 & - & - & - & - & - & - \\
\hline Constant & 3.420 & 3.209 & 4.148 & 3.228 & 3.376 & 3.188 & 2.250 & .115 & 2.151 & $0.117^{* * *}$ & 2.151 & $0.117 * * *$ \\
\hline $\bar{N}$ & \multicolumn{2}{|c|}{47636} & \multicolumn{2}{|c|}{47636} & \multicolumn{2}{|c|}{47636} & \multicolumn{2}{|c|}{47636} & \multicolumn{2}{|c|}{47636} & \multicolumn{2}{|c|}{47636} \\
\hline Adjusted $\mathrm{R}^{2}$ & \multicolumn{2}{|c|}{.2990} & \multicolumn{2}{|c|}{.2987} & \multicolumn{2}{|c|}{.2987} & \multicolumn{2}{|c|}{.2995} & \multicolumn{2}{|c|}{.2988} & \multicolumn{2}{|c|}{.2988} \\
\hline
\end{tabular}

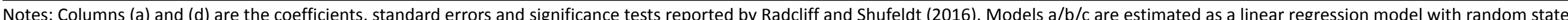

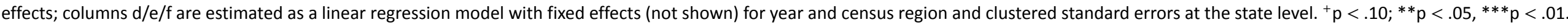




\section{Conclusion}

Rising economic inequality within the United States and other advanced economies has generated much scholarly attention over the past two decades. For example, the American Political Science Association released a report (2010) from top scholars warning of serious consequences for American democracy from sharply rising inequality. Scholars also commonly acknowledge that public policy choices significantly influence the level of economic inequality, and often for the worse (see for example Bonica et al., 2013). Faced with concerns of this kind, scholars, advocates, and concerned citizens alike have considered possible political reforms or mechanisms that might reduce inequality.

Given that direct democracy still enjoys high levels of popularity in many quarters, it is perhaps unsurprising that some look to mechanisms such as the ballot initiative process as a partial solution to growing inequality. Yet based on a range of evidence, we see no reason to think that income inequality in the United States would be reduced if more states established an initiative process or states that had it made greater use of ballot measures. And for readers from other countries, our findings suggest caution in believing that adding American style direct democracy would help address their own economic inequality issues.

\section{Acknowledgments}

We would like to thank Benjamin Radcliff and Gregory Shufeldt for generously sharing their data and coding.

\section{Conflict of Interests}

The authors declare no conflict of interests.

\section{References}

American Political Science Association. (2010). Task force on inequality and American democracy. 2004. American democracy in an age of rising inequality. Perspectives on Politics, 2(4), 651-666.

Ballotpedia: The encyclopedia of American politics. (n.d.-a). Initiative States Compared by Number of Initiatives on Their Ballot. Retrieved from https:// ballotpedia.org/Initiative_states_compared_by_ number_of_initiatives_on_their_ballot

Ballotpedia: The encyclopedia of American politics. (n.d.-b). List of California Ballot Propositions. Retrieved from https://ballotpedia.org/List_of_ California_ballot_propositions

Boehmke, F. (2005). The indirect effect of direct legislation: How institutions shape interest group systems. Columbus, $\mathrm{OH}$ : Ohio State University Press.

Bonica, A., McCarty, N., Poole, K. T., \& Rosenthal, H. (2013). Why hasn't democracy slowed rising inequality? Journal of Economic Perspectives, 27(3),
103-124.

Broder, D. (2001). Democracy derailed: Initiative campaigns and the power of money. San Diego, CA: Harcourt.

Bucci, L. C. (2018a). Organized labor's check on rising economic inequality in the U.S. states. State Politics \& Policy Quarterly, 18(2), 148-173.

Bucci, L. C. (2018b). Replication data for: Organized labor's check on rising income inequality. in the U.S. states. UNC Dataverse. https://doi.org/10.15139/S3/ L95PUM

Chávez, L. (1998). The color bind: California's battle to end affirmative action. Berkeley, CA: University of California Press.

Cummings, K. M., \& Proctor, R. N. (2014). The changing public image of smoking in the United States: 1964-2014. Cancer Epidemiology and Prevention Biomarkers, 23(1), 32-36.

Dorn, D., Fischer, J. A. V., Kirchgässner, G., \& Sousa-Poza, A. (2008). Direct democracy and life satisfaction revisited: New evidence for Switzerland. Journal of Happiness Studies, 9(2), 227-255.

Dyck, J. J., \& Lascher, E. L. (2019). Initiatives without engagement: A realistic appraisal of direct democracy's secondary effects. Ann Arbor, MI: University of Michigan Press.

Ellis, R. J. (2002). Democratic delusions: The initiative process in America. Lawrence, KS: University Press of Kansas.

Eule, J. N. (1990). Judicial review of direct democracy. Yale Law Journal, 99(7), 1503-1590.

Feld, L. P., Fischer, J. A. V., \& Kirchgässner, G. (2010). The effect of direct democracy on income redistribution: Evidence for Switzerland. Economic Inquiry, 48(4), 817-840.

Franko, W. W., \& Witko, C. (2018). The new economic populism: How states respond to economic inequality. New York, NY: Oxford University Press.

Frey, B. S., \& Stutzer, A. (2000). Happiness prospers in democracy. Journal of Happiness Studies, 1(1), 79-102.

Gerber, E. R. (1996). Legislative response to the threat of popular initiatives. American Journal of Political Science, 40(1), 99-128.

Gilens, M. (1999). Why Americans hate welfare: Race, media, and the politics of antipoverty policy. Chicago, IL: University of Chicago Press.

Graetz, M., \& Shapiro, I. (2011). Death by a thousand cuts: The fight over taxing inherited wealth. Princeton, NJ: Princeton University Press.

Harms, P., \& Zink, S. (2003). Limits to redistribution in a democracy: A survey. European Journal of Political Economy, 19(4), 651-668.

Hinnerich, B. T., \& Pettersson-Lidbom., P. (2014). Democracy, redistribution, and political participation: Evidence from Sweden 1919-1938. Econometrica, 82(3), 961-993.

Kelly, N. J., \& Witko, C. (2012). Federalism and American 
inequality. The Journal of Politics, 74(2), 414-426.

Klarner, C. (2015). State economic and government finance data. Harvard Dataverse. https://doi.org/10. 7910/DVN/CJBTGD

Lax, J. R., \& Phillips, J. H. (2009). Gay rights in the states: Public opinion and policy responsiveness. American Political Science Review, 103(3), 367-386.

Magleby, D. B. (1984). Direct legislation: Voting on ballot propositions in the United States. Baltimore, MD: Johns Hopkins University Press.

Matsusaka, J. G. (2004). For the many or the few: The initiative, public policy, and American democracy. Chicago, IL: University of Chicago Press.

Monogan, J., Gray, V., \& Lowery, D. (2009). Public opinion, organized interests, and policy congruence in initiative and noninitiative US states. State Politics \& Policy Quarterly, 9(3), 304-324.

National Conference of State Legislatures. (n.d.). Statewide ballot measures database. National Conference of State Legislatures. Retrieved from http://www.ncsl.org/research/elections-andcampaigns/ballot-measures-database.aspx

Putnam, R. D. (2000). Bowling alone: America's declining social capital. New York, NY: Palgrave Macmillan.

Radcliff, B., \& Shufeldt, G. (2016). Direct democracy and subjective well-being: The initiative and life satisfaction in the American states. Social Indicators Research, 128(3), 1405-1423.

Sances, M. W. (2016). The distributional impact of greater responsiveness: Evidence from New York towns. The Journal of Politics, 78(1), 105-119.

Sances, M. W. (2018). Something for something: How and why direct democracy impacts service quality. Quarterly Journal of Political Science, 13(1), 29-57.

Sears, D. O., \& Citrin, J. (1982). Tax revolt: Something for nothing in California. Cambridge, MA: Harvard University Press.

Shapiro, I. (2002). Why the poor don't soak the rich. Daedalus, 131(1), 118-128.

Smith, D. A., \& Tolbert, C. J. (2004). Educated by initiative: The effects of direct democracy on citizens and political organizations in the American states. Ann Arbor, MI: University of Michigan Press.

The Ballot Initiative Strategy Center. (n.d.). The Ballot Initiative Strategy Center. Retrieved from https://ballot. org/who-we-are

University of California Hastings Law Library. (n.d.). California ballot measures. University of California, Hastings College of the Law. Retrieved from https://www. uchastings.edu/academics/library/ca-ballots

United States Department of Labor. (n.d.). Wage and hour division-Changes in basic minimum wages in non-farm employment under state law: Selected years 1968 to 2018. United States Department of Labor. Retrieved from https://www.dol.gov/whd/ state/stateminwagehis.htm

Verba, S., Schlozman, K. L., \& Brady, H. E. (1995). Voice and equality: Civic voluntarism in American politics. Cambridge, MA: Harvard University Press.

\section{About the Authors}

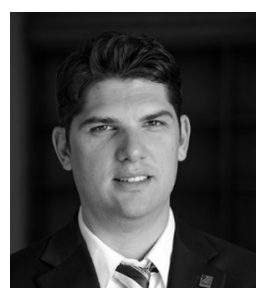

Joshua J. Dyck is Associate Professor of political science and Co-Director of the Center for Public Opinion at the University of Massachusetts Lowell. He is the author of Initiatives without Engagement: A realistic appraisal of direct democracy's secondary effects (2019, University of Michigan Press) with Edward L. Lascher, Jr. and more than two dozen peer-reviewed journal articles on elections, public opinion, voting behavior, social context, and the politics of direct democracy.

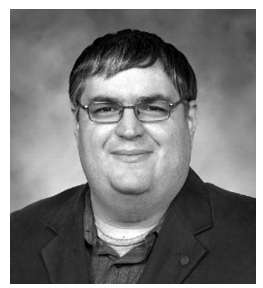

Wesley Hussey is an Associate Professor of political science at California State University, Sacramento, specializing in California government and politics. He is the academic advisor for the respected Sacramento Semester internship program and is the author of numerous peer-review journal articles about the state. A member of the American Western State Budget Roundtable, Hussey co-authors an annual report on the California budget.

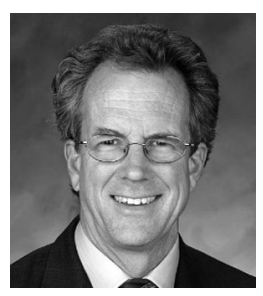

Edward L. Lascher, Jr. is Professor of public policy and administration at California State University, Sacramento, where he has also served as Interim Dean, department chair, and acting director of the Center for California Studies. His research has focused on the ballot initiative process, political parties, regulatory policy, elections, pedagogy, and the politics of ideas. 


\section{Appendix}

In this supplementary appendix, we explain in more detail our replication and extension of the Radcliff and Shufeld (2016, hereafter R\&S) analysis of the DDB Life Style Survey. The survey contains yearly data from 1975 to 1998 , including a question on life satisfaction, the focus of this study, from 1985 to 1998. In preparing this study, we contacted the authors and they generously shared their level-2 data file with us. This and the details from the original article led us to be able to replicate six of the seven statistical models presented in R\&S.

In completing the replication, we noted both a technical coding error and also a conceptual error in the measurement of "density of ballot initiatives," which is measured as a cumulative number of initiatives from 1960 up to the year of the survey. It appears the authors have only assigned non-zero values to this variable in years where a state actually added values to the total. This means that for most states in odd years, states with long cumulative histories of initiative usage like California, Oregon, and Colorado were coded as zero. We illustrate the coding error in Figure A1. Rather than observing a steadily increasing relationship where each new initiative increases the total \# of initiatives measurement (a measure of historical initiative usage/density), the patterns are zig-zags. The exception is Washington State, which regularly has odd-year statewide initiative elections. In two of the seven models that R\&S present, they measure the initiative process using a simple dummy variable. We discovered a nearly identical error in this measure. In years that state did not have any initiatives, the variable is coded as zero instead of 1 . When corrected, $45.7 \%$ of the respondents in the DDB Life Style survey from 1985-1998 live in initiative states, but according to this coding, fewer than $20 \%$ of the respondents are coded as living in initiatives states; almost none are coded as living in initiative states during odd years. We detail the error of this coding in Figure A2.

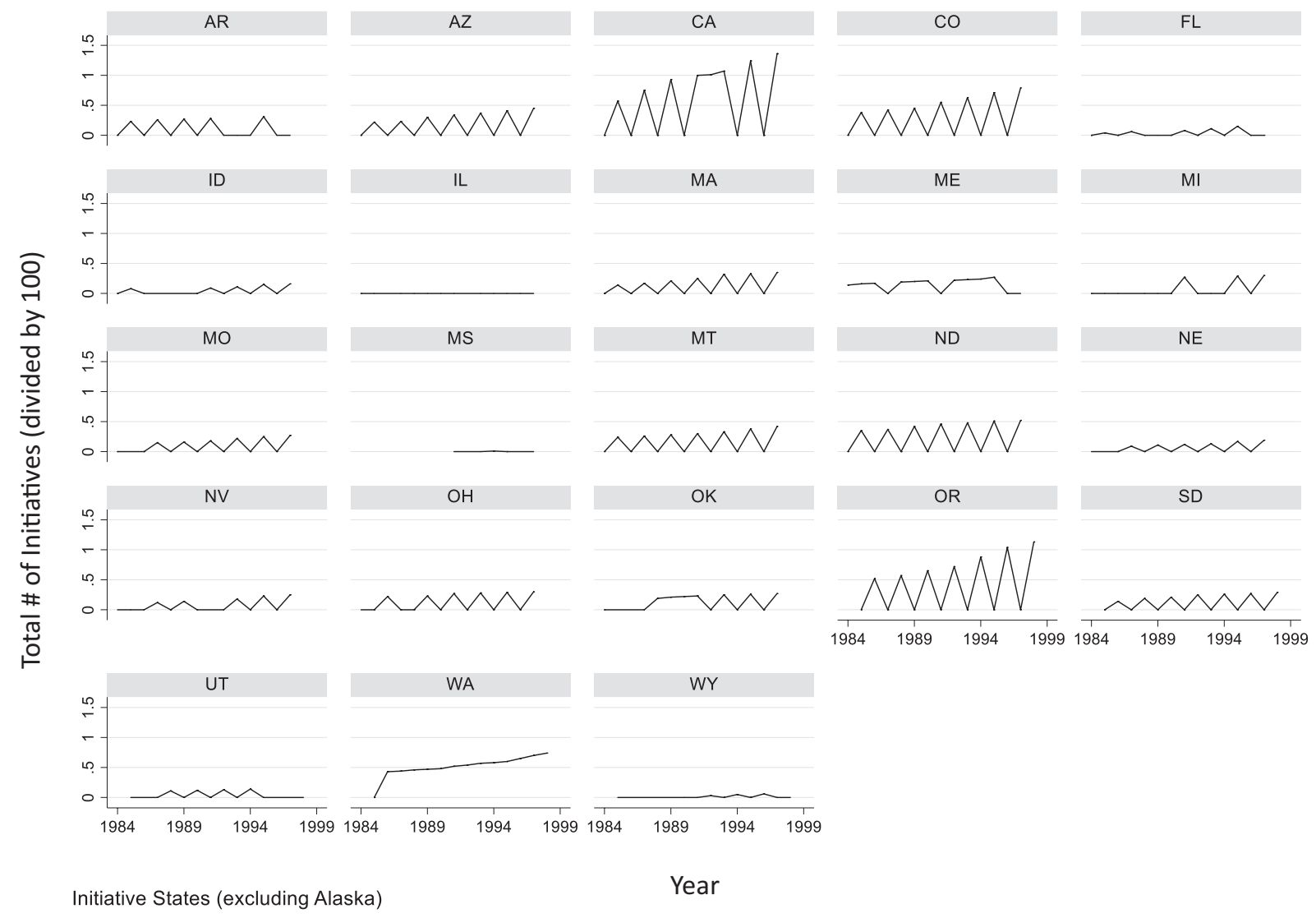

Figure A1. Visual depiction of coding problems of initiative variable in R\&S. Note: Figure depicts the coding error in the key explanatory variable "Total \# of Initiatives from 1960 to the current survey year." States that did not have initiatives in the survey year were coded as zero instead of having their previous year codes added forward. For states without odd year initiatives, this effectively made their codes zero in almost all odd years of the data.

Our first task is to correct both of these measures and to re-estimate the models. However, once corrected, the initiative density measure still suffers from a conceptual problem. Because it is anchored with the year 1960, the measure will always increase and never decrease, which builds an upward sloping time trend into the explanatory variable of interest. As R\&S suggest by explicitly modeling time in their models, time is an important construct in the measurement of life satisfaction. Therefore, this introduction of a trend may be unintentionally biasing the results. There is an easy fix for this. To preserve 
the measure of density, we can simply use the average number of initiatives from 1960 to the survey year; this allows the measure to vary and to either increase or decrease based on how frequently initiatives are used in ensuing years. We therefore first proceed by re-estimating the models from Table 1 in R\&S in the main text of the article as Table 4 and from Tables 2 and 3 from R\&S in Appendix Tables A1 and A2. For the five models that use initiative density as an explanatory variable, we present a variant of the model with the corrected measure, and also with an alternate measure of density using the average number of initiatives from 1960 to the survey year. For the initiative dummy models, we present the replication followed by the corrected model. We also present visual depictions of the interaction effects for the seven corrected models and the five initiative average models.

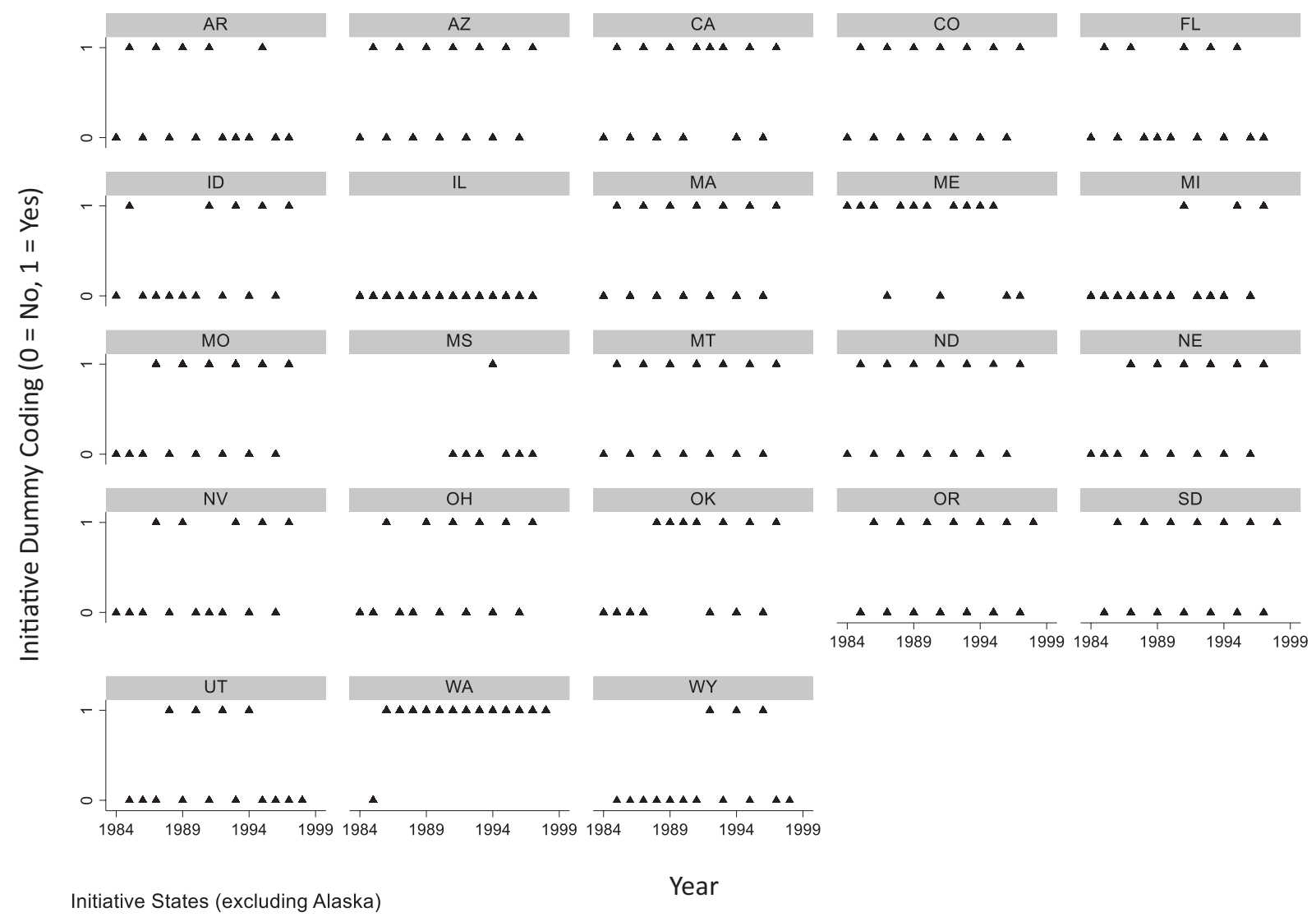

Figure A2. Visual depiction of coding problems of Initiative Dummy Variable in R\&S. Note: Figure depicts the coding error in the key explanatory variable "Yes/No has initiative." States that did not have initiatives in the survey year were coded as zero instead of 1 . For states without odd year initiatives, this effectively made their codes zero in almost all odd years of the data. 
Table A1. Initiatives, income and life satisfaction (replication of Radcliff \& Shufeldt, 2016, Table 2).

\begin{tabular}{|c|c|c|c|c|c|c|c|c|c|c|c|c|c|c|c|c|}
\hline & \multicolumn{2}{|c|}{$\begin{array}{l}\text { R\&S } \\
\text { Table } 2 \\
\text { Model a } \\
\text { (a) }\end{array}$} & \multicolumn{2}{|c|}{$\begin{array}{l}\text { Replication } \\
\text { with initiative } \\
\text { variable } \\
\text { corrected (b) }\end{array}$} & \multicolumn{2}{|c|}{$\begin{array}{c}\text { Replication } \\
\text { with initiative } \\
\text { average (c) }\end{array}$} & \multicolumn{2}{|c|}{$\begin{array}{c}\text { R\&S } \\
\text { Table 2, Model b } \\
\text { Without CA } \\
\text { \& OR (d) }\end{array}$} & \multicolumn{2}{|c|}{$\begin{array}{c}\text { Replication } \\
\text { with initiative } \\
\text { variable } \\
\text { corrected (e) }\end{array}$} & \multicolumn{2}{|c|}{$\begin{array}{l}\text { Replication } \\
\text { with initiative } \\
\text { average (f) }\end{array}$} & \multicolumn{2}{|c|}{$\begin{array}{c}\text { R\&S } \\
\text { Table 2, Model c } \\
\text { Initiative }(0,1) \\
\text { model (g) }\end{array}$} & \multicolumn{2}{|c|}{$\begin{array}{c}\text { Replication } \\
\text { with initiative } \\
\text { dummy variable } \\
\text { corrected (h) }\end{array}$} \\
\hline & Coef & SE & Coef & SE & Coef & SE & Coef & SE & Coef & SE & Coef & SE & Coef & SE & Coef & SE \\
\hline itiative Density & .110 & $.030^{* * *}$ & .111 & $.043^{* * *}$ & .032 & $.014^{* *}$ & .209 & $.101^{* *}$ & 119 & .091 & .018 & .028 & - & - & - & - \\
\hline 1. & - & - & - & - & - & - & - & - & - & - & - & - & .061 & $.029 * * *$ & .04 & $.023^{+}$ \\
\hline me & .020 & $.008^{* * *}$ & .020 & $.008^{* *}$ & .020 & $.008^{* *}$ & .020 & $.008^{* * *}$ & 019 & $.008^{* *}$ & .019 & $.008 * *$ & .020 & $.008^{* * *}$ & .020 & $.008^{* *}$ \\
\hline Initiative X Income & .010 & .005 & -.006 & .005 & .002 & .002 & -.018 & $012^{+}$ & $-00 \quad-3$ & & 001 & & -.007 & .00 & -.002 & .003 \\
\hline \multicolumn{17}{|l|}{ State Level Vars } \\
\hline ate Population & 000 & 00 & .000 & .000 & .000 & .0 & -.000 & .00 & .000 & $.0 c$ & .000 & .0 & .000 & .0 & .000 & $.000 * *$ \\
\hline & .000 & $.000^{+}$ & .000 & .000 & .000 & $.000^{+}$ & .000 & .00 & .00 & .00 & .000 & .00 & .000 & .00 & .000 & $.000^{+}$ \\
\hline & .194 & $.088^{* *}$ & .213 & $.089 * *$ & .214 & $.089 * *$ & .208 & $.091 * *$ & .204 & $.091 *$ & .213 & $.091 * *$ & .208 & $.088 * *$ & .184 & $.088 * *$ \\
\hline oclal capital & .022 & $.017^{+}$ & .016 & .017 & .018 & .017 & .019 & $.017^{+}$ & .01 & .018 & .019 & .018 & .022 & $.017^{+}$ & .016 & .017 \\
\hline \multicolumn{17}{|l|}{ Ind'I Level Vars } \\
\hline nan & 394 & $4 * * *$ & .394 & $34 * * *$ & 394 & $.004^{* * *}$ & .390 & .004 & 390 & $.004^{* * *}$ & 390 & .004 & .394 & .00 & 394 & $.004^{* * *}$ \\
\hline & 0 & & -.0 & & -.0 & & & & -.0 & & -.0 & & -.0 & & & \\
\hline nen & -.314 & .035 & -.31 & .03 & -.314 & .03 & -.293 & & -.29 & & -.293 & & -.313 & & -.3 & \\
\hline & & & 0 & & 0 & & & & & & 0 & & & & & \\
\hline Shildr & -.109 & .013 & $-.1 c$ & .01 & -.10 & .01 & -.1 & .01 & -.11 & & -.116 & & -.109 & & -.108 & \\
\hline & 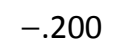 & & -.2 & & $-.2 c$ & & -.1 & & -.1 & & -.1 & & -.200 & & -.199 & \\
\hline & .0 & .02 & -.00 & .02 & -.00 & .02 & .0 & .03 & -.0 & .0 & -.0 & .0 & .003 & .0 & .003 & .02 \\
\hline & $c^{2}+2$ & & -.0 & & -.0 & & -.0 & & -.0 & & -.042 & & -.0 & & -.042 & \\
\hline $\mathrm{ge}^{2}$ & .000 & .000 & .00 & .000 & .00 & .000 & .000 & .00 & .000 & & .000 & .00 & .000 & .00 & .000 & $.000 * * *$ \\
\hline & & & .2 & & .2 & $.031^{* * *}$ & .2 & .034 & .2 & .03 & .2 & .03 & .218 & & & \\
\hline & & & .0 & & .05 & $.027^{+}$ & .0 & .02 & .02 & .02 & .0 & .02 & .0 & & .051 & $.027^{+}$ \\
\hline Vlar & .294 & $.021 *$ & .29 & .0 & .294 & .021 & .291 & .02 & .29 & & .291 & & .2 & & .294 & \\
\hline 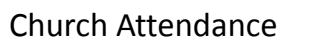 & 030 & .002 & .03 & & .03 & & .03 & & .03 & & .032 & & $.0 \Xi$ & & .030 & $.002^{* * *}$ \\
\hline Socia & .106 & $.005^{* * *}$ & .106 & .005 & .10 & .005 & .106 & .00 & .10 & & .106 & & . 106 & & .106 & .00 \\
\hline Heal t & .148 & $.004^{*}$ & .14 & .004 & .14 & $.004^{* *}$ & .14 & & .14 & & .1 & & .1 & & .148 & $.004 * * *$ \\
\hline Tran & & .036 & .0 & .0 & .07 & .036 & & .03 & & $.038 * *$ & & $.038^{* *}$ & .066 & .03 & .067 & $.036^{+}$ \\
\hline & 00 & .004 & -.00 & & -.00 & & -.0 & & -0 & & 0 & & -0 & & & $.004 * *$ \\
\hline Year & 01 & .002 & -.002 & $.002 * *$ & -.002 & $.002 * *$ & -.001 & .002 & -.001 & .002 & -.001 & .002 & -.001 & .002 & -.001 & .002 \\
\hline Constant & 420 & 3.209 & 6.679 & 3.770 & 5.637 & 3.694 & 3.420 & 3.209 & 4.847 & 3.947 & 4.154 & 3.929 & 4.405 & 3.643 & 4.271 & 3.627 \\
\hline & \multirow{2}{*}{\multicolumn{2}{|c|}{47636}} & \multicolumn{2}{|c|}{47636} & \multicolumn{2}{|c|}{47636} & \multicolumn{2}{|c|}{42053} & \multicolumn{2}{|c|}{42053} & \multicolumn{2}{|c|}{42053} & \multirow{2}{*}{\multicolumn{2}{|c|}{47636}} & \multirow{2}{*}{\multicolumn{2}{|c|}{47636}} \\
\hline Adjusted $R^{2}$ & & & & & & & & & & & & & & & & \\
\hline
\end{tabular}

Notes: ${ }^{*} p<.10 ;{ }^{* *} p<.05,{ }^{* * *} p<.01$. All models in this table are estimated using linear regression with random state effects. Columns a, $d$, and $g$ are the coefficients, standard errors and significance tests reported by Radcliff and Shufeldt (2016). Models b, $c, e, f$, and $h$ are estimated as linear regression models with random state effects.

Politics and Governance, 2019, Volume 7, Issue 2, Pages 380-409 
Table A2. Initiatives, income and life satisfaction (replication of Radcliff \& Shufeldt 2016, Table 3).

\begin{tabular}{|c|c|c|c|c|c|c|c|c|c|c|}
\hline & \multicolumn{2}{|c|}{$\begin{array}{c}\text { R\&S } \\
\text { Table 3, Model } 1 \text { (a) }\end{array}$} & \multicolumn{2}{|c|}{$\begin{array}{l}\text { Replication with initiative } \\
\text { variable correction (b) }\end{array}$} & \multicolumn{2}{|c|}{$\begin{array}{c}\text { Replication with } \\
\text { initiative average (c) }\end{array}$} & \multicolumn{2}{|c|}{$\begin{array}{c}\text { R\&S } \\
\text { Table 2, Model } 2 \text { (d) }\end{array}$} & \multicolumn{2}{|c|}{$\begin{array}{l}\text { Replication with initiative } \\
\text { dummy variable corrected (e) }\end{array}$} \\
\hline & Coef & SE & Coef & SE & Coef & SE & Coef & SE & Coef & SE \\
\hline Initiative Density & .100 & $.050 * *$ & .097 & $.045^{* *}$ & .027 & $.015^{+}$ & - & - & - & - \\
\hline Initiative $(0,1)$ & - & - & - & - & - & - & .057 & $.028 * * *$ & 0.041 & $0.023^{+}$ \\
\hline Individual Income & .005 & $.002 * * *$ & .005 & $.002^{* *}$ & .005 & $.002^{* *}$ & .005 & $.002 * *$ & 0.005 & $0.002 * *$ \\
\hline Initiative X Income & -.010 & $.005^{* *}$ & -.006 & .005 & -.002 & .002 & -.007 & $.003 * *$ & -0.002 & 0.003 \\
\hline \multicolumn{11}{|l|}{ State Level Vars } \\
\hline State Population & -.000 & .000 & .000 & $.000 * *$ & .000 & $.000 * *$ & -.000 & .000 & 0.000 & $0.000 * *$ \\
\hline State Income (PC) & .000 & .000 & .000 & $.000^{*}$ & .000 & $.000^{+}$ & .000 & .000 & 0.000 & $0.000^{+}$ \\
\hline Racial Diversity & .129 & .096 & .144 & $.083^{* *}$ & .147 & $.084^{+}$ & .130 & .100 & 0.144 & $0.082^{+}$ \\
\hline Social Capital & .011 & .018 & .008 & .017 & .010 & .017 & .011 & .019 & 0.011 & 0.017 \\
\hline \multicolumn{11}{|l|}{ Ind'I Level Vars } \\
\hline Financial Satisfaction & .394 & $.004 * * *$ & .394 & $.004 * * *$ & .394 & $.004 * * *$ & .394 & $.004 * * *$ & 0.394 & $0.004 * * *$ \\
\hline Education & -.019 & $.005^{* * *}$ & -.019 & $.005 * * *$ & -.019 & $.005 * * *$ & -.018 & $.005 * * *$ & -0.019 & $0.005^{* * *}$ \\
\hline Unemployed $(0,1)$ & -.310 & $.035^{* * *}$ & -.312 & $.035 * * *$ & -.312 & $.035 * * *$ & -.311 & $.035 * * *$ & -0.312 & $0.035^{* * *}$ \\
\hline Sex & .087 & $.012 * * *$ & .087 & $.012 * * *$ & .087 & $.012 * * *$ & .088 & $.011 * * *$ & 0.087 & $0.012 * * *$ \\
\hline Children & -.109 & $.013 * * *$ & -.109 & $.013 * * *$ & -.109 & $.013 * * *$ & -.109 & $.013 * * *$ & -0.109 & $0.013^{* * *}$ \\
\hline Black & -.197 & $.025 * * *$ & -.197 & $.025 * * *$ & -.197 & $.025 * * *$ & -.196 & $.024 * * *$ & -0.197 & $0.025 * * *$ \\
\hline Race-Other & .004 & .028 & .002 & .028 & .003 & .028 & .004 & .028 & 0.005 & 0.028 \\
\hline Age & -.042 & $.002 * * *$ & -.042 & $.002 * * *$ & -.042 & $.002 * * *$ & -.042 & $.002 * * *$ & -0.042 & $0.002 * * *$ \\
\hline Age $^{2}$ & .000 & $.000 * * *$ & .000 & $.000 * * *$ & .000 & $.000 * * *$ & .000 & $.000 * * *$ & 0.000 & $0.000 * * *$ \\
\hline Widowed & .215 & $.031 * * *$ & .216 & $.031 * * *$ & .215 & $.031 * * *$ & .215 & $.031 * * *$ & 0.215 & $0.031 * * *$ \\
\hline Divorced & .048 & $.027 * *$ & .048 & $.027^{+}$ & .048 & $.027^{+}$ & .047 & $.026^{+}$ & 0.048 & $0.027^{+}$ \\
\hline Married & .293 & $.021 * * *$ & .292 & $.021 * * *$ & .291 & $.021 * * *$ & .291 & $.029 * * *$ & 0.291 & $0.021 * * *$ \\
\hline Church Attendance & .030 & $.002 * * *$ & .030 & $.002 * * *$ & .030 & $.002 * * *$ & .030 & $.002 * * *$ & 0.030 & $0.002 * * *$ \\
\hline Social Trust & .105 & $.005^{* * *}$ & .106 & $.005^{* * *}$ & .105 & $.005^{* * *}$ & .105 & $.005^{* * *}$ & 0.105 & $0.005^{* * *}$ \\
\hline Health of $R$ & .148 & $.004 * * *$ & .148 & $.004^{* * *}$ & .148 & $.004^{* * *}$ & .148 & $.004 * * *$ & 0.148 & $0.004^{* * *}$ \\
\hline Constant & \multicolumn{2}{|c|}{ Not reported } & 2.131 & $.084^{* * *}$ & 2.133 & $.085 * * *$ & \multicolumn{2}{|c|}{ Not reported } & 2.124 & $0.085^{* * *}$ \\
\hline Residual variance & \multicolumn{2}{|c|}{1.22} & \multicolumn{2}{|c|}{1.511} & \multicolumn{2}{|c|}{1.511} & \multicolumn{2}{|c|}{1.22} & \multicolumn{2}{|c|}{1.511} \\
\hline Intercept variance for state & \multicolumn{2}{|c|}{.028} & \multicolumn{2}{|c|}{$>.001$} & \multicolumn{2}{|c|}{$>.001$} & \multicolumn{2}{|c|}{.028} & \multicolumn{2}{|c|}{$>.001$} \\
\hline Intercept variance for state-years & \multicolumn{2}{|c|}{.016} & \multicolumn{2}{|c|}{$>.001$} & \multicolumn{2}{|c|}{$>.001$} & \multicolumn{2}{|c|}{.104} & \multicolumn{2}{|c|}{$>.001$} \\
\hline Log restricted-likelihood & \multicolumn{2}{|c|}{-77594.2} & \multicolumn{2}{|c|}{-77432.1} & & & & & & 2.4 \\
\hline Wald Test & 202 & $* * *$ & 203 & $; * *$ & 203 & $4 * * *$ & 202 & $9 * * *$ & 203 & $2 * * *$ \\
\hline $\mathrm{N}$ (stats) & & & & & & & & & & \\
\hline $\mathrm{N}$ (state years) & & & & & & & & & & \\
\hline $\mathrm{N}$ (individuals) & & & & & & & & & & \\
\hline
\end{tabular}

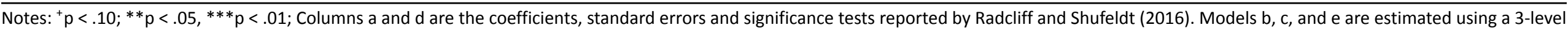
multilevel mixed linear model: individuals (level 1 ) in state-years (level 2 ) in states (level 3). Year dummies are included in all models, but not presented. 
In all seven models where the measure of initiative is simply corrected, the sign on the interaction term, measuring the difference in the slope of the effect of the initiative on life satisfaction moves from statistically significant to not statistically significant. Therefore, it appears the findings presented in R\&S are a function of a data coding error with regards to measurement of initiative context, both as a dummy variable and as density from 1960 to the year of the survey. None of the interaction terms are significant when we move to a model with the initiative average variable.

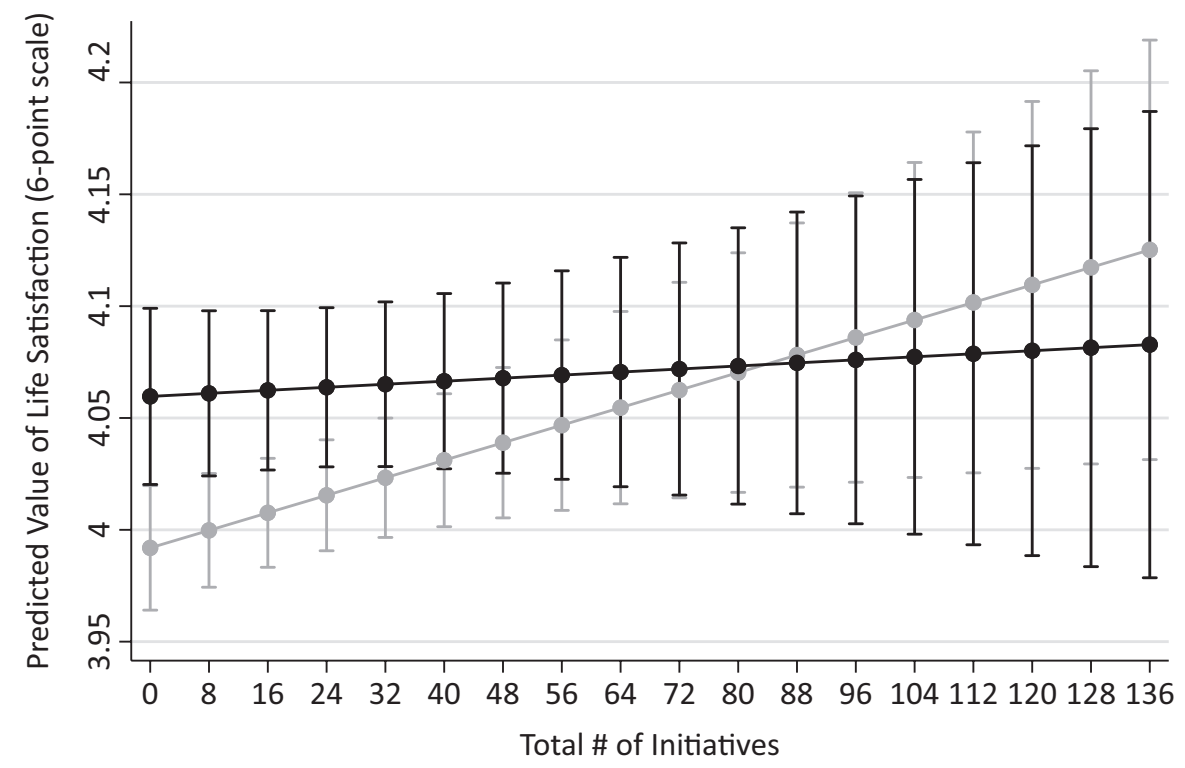

$\longrightarrow$ under $\$ 10,000 \quad \longrightarrow \$ 100,000$ or more

Figure A3a. Interaction of initiative and income, from Table 5 (b).

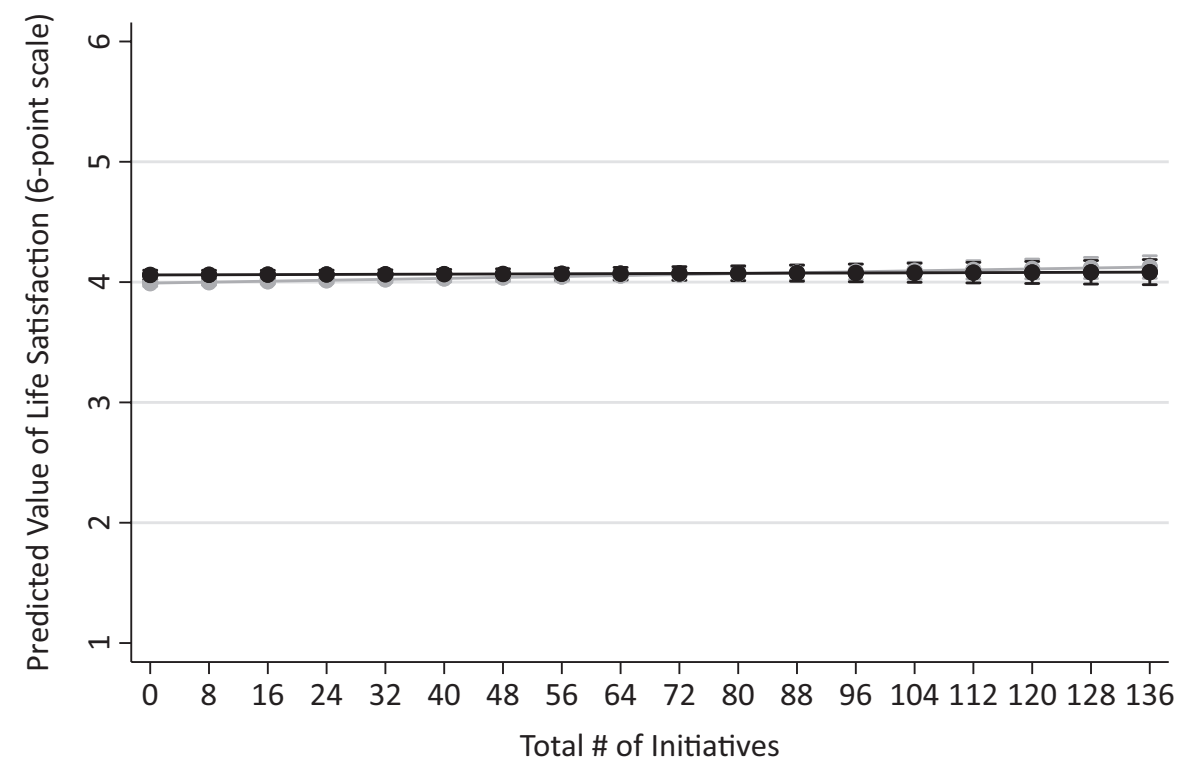

$\longrightarrow$ under $\$ 10,000 \quad \longrightarrow \$ 100,000$ or more

Figure A3b. Figure A3a, with the $\mathrm{Y}$-axis rescaled to represent the full range of plausible values. 


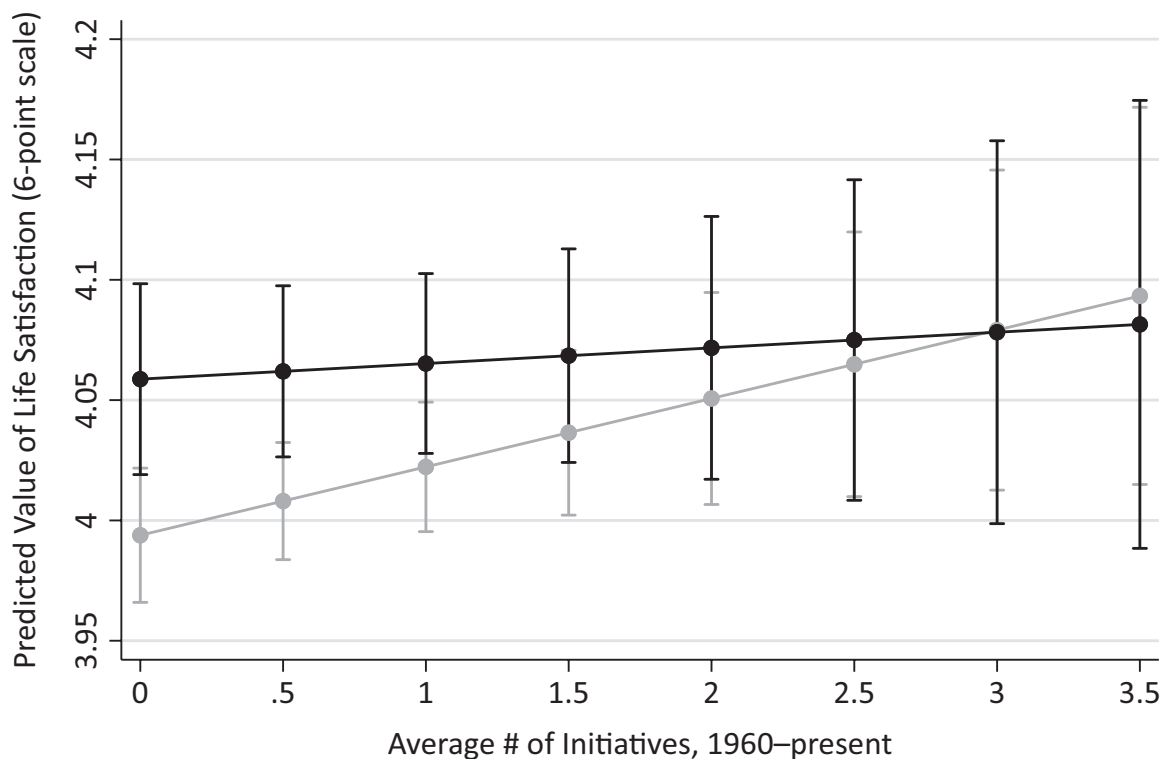

$\longrightarrow$ under $\$ 10,000 \longrightarrow \$ 100,000$ or more

Figure A4a. Interaction of initiative and income, from Table 4 (c).

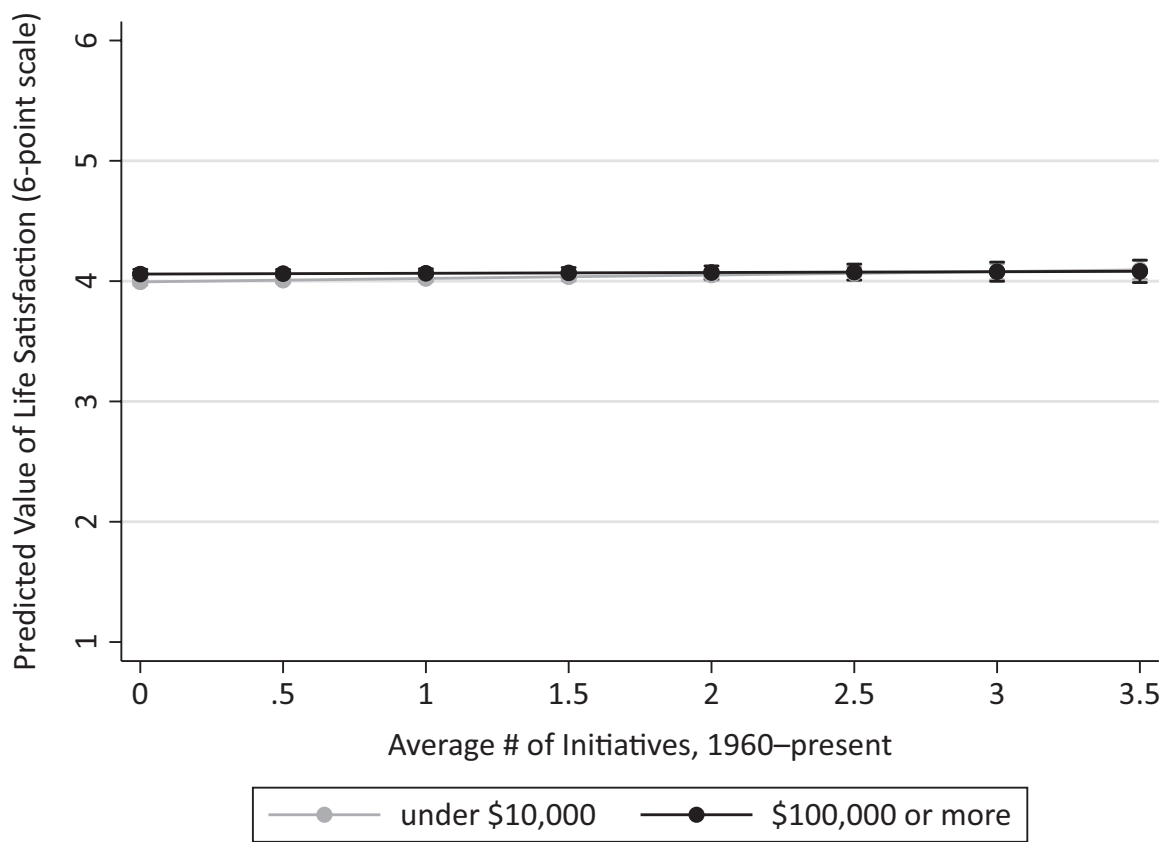

Figure A4b. Figure A4a, with the Y-axis rescaled to represent the full range of plausible values. 


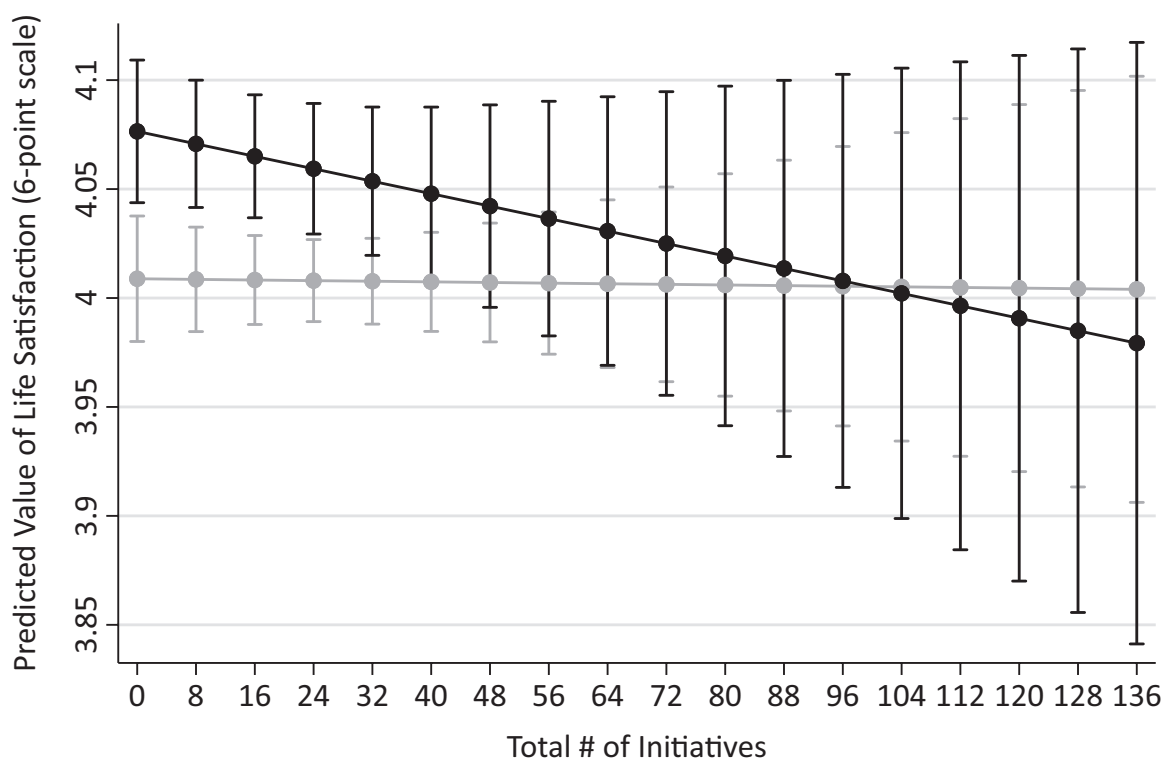

$\longrightarrow$ under $\$ 10,000 \longrightarrow \$ 100,000$ or more

Figure A5a. Interaction of initiative and income, from Table 4 (e).

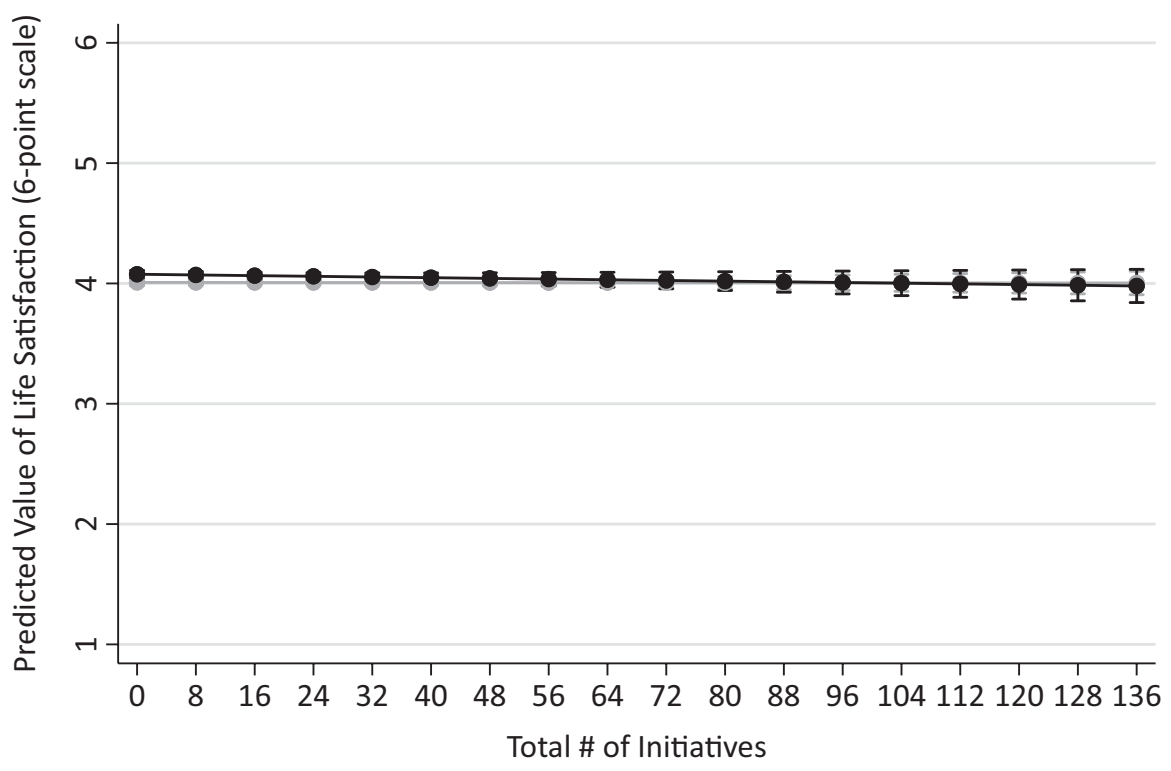

$\longrightarrow$ under $\$ 10,000 \longrightarrow \$ 100,000$ or more

Figure A5b. Figure A5a, with the $\mathrm{Y}$-axis rescaled to represent the full range of plausible values. 


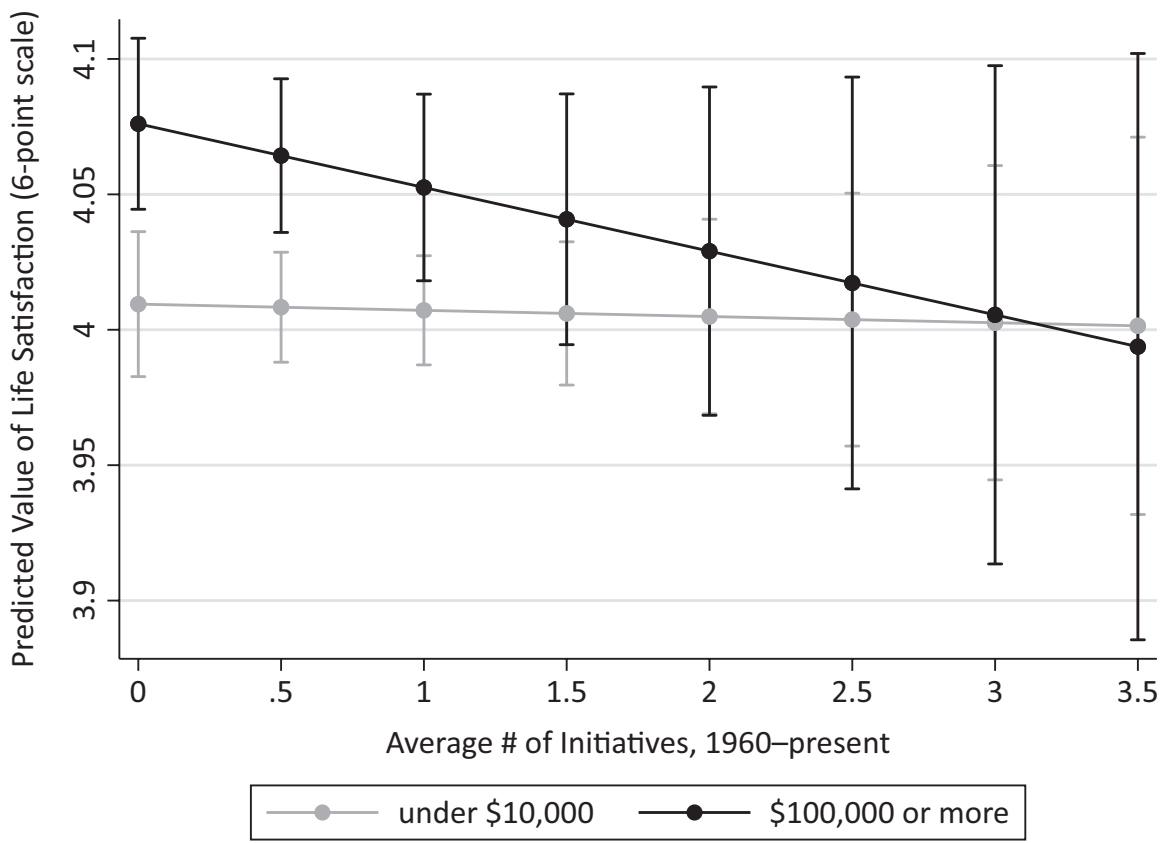

Figure A6a. Interaction of initiative and income, from Table 4 (f).

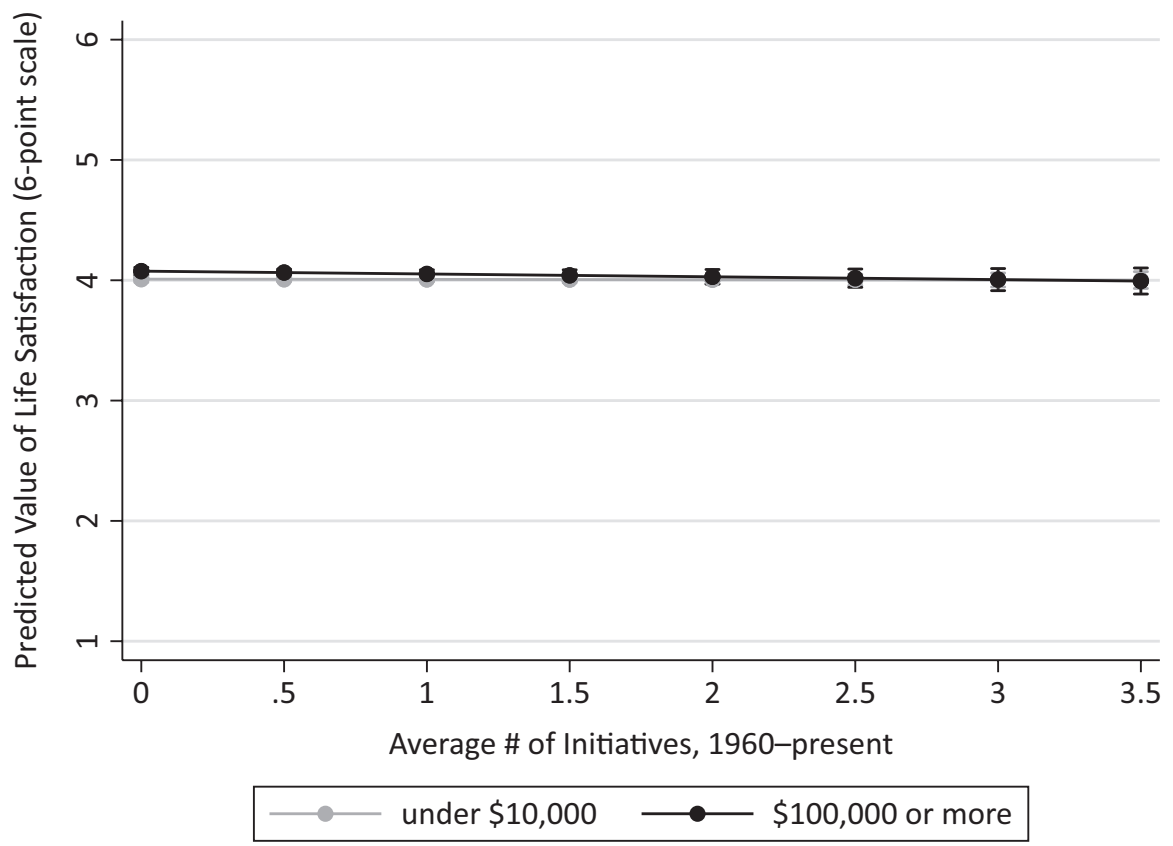

Figure A6b. Figure A6a, with the Y-axis rescaled to represent the full range of plausible values. 


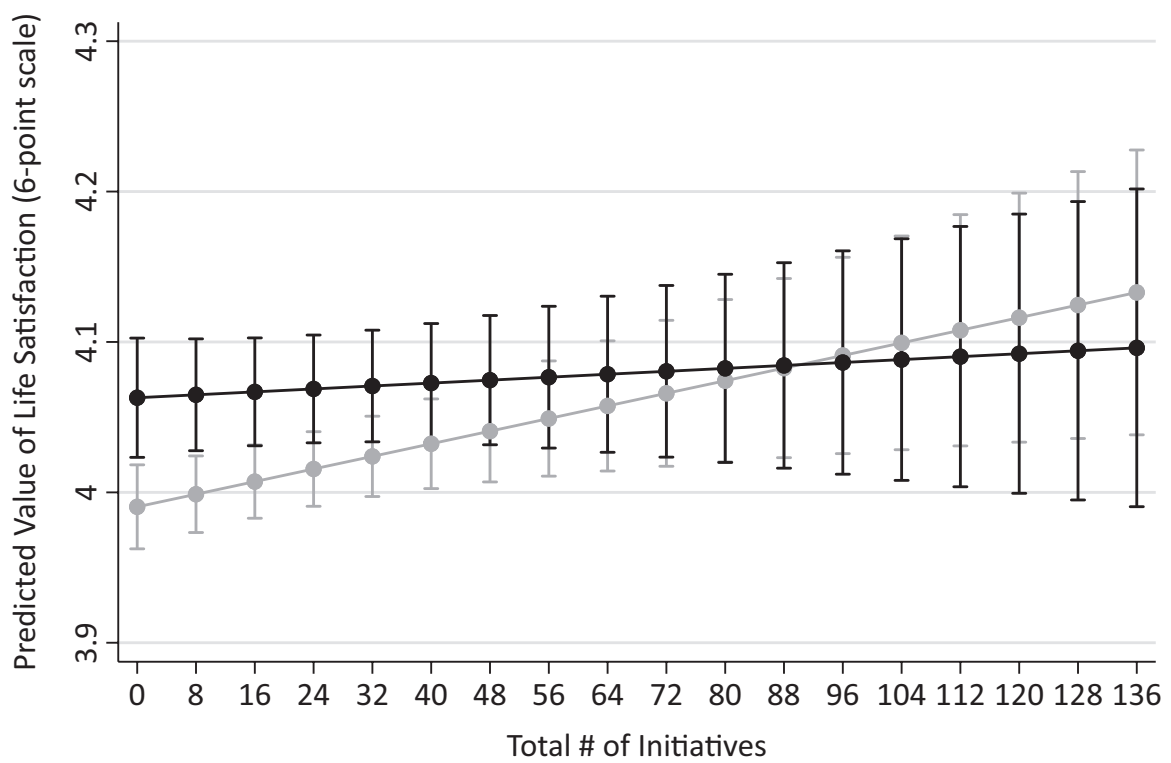

$\longrightarrow$ under $\$ 10,000 \longrightarrow \$ 100,000$ or more

Figure A7a. Interaction of initiative and income, from Table A1 (b).

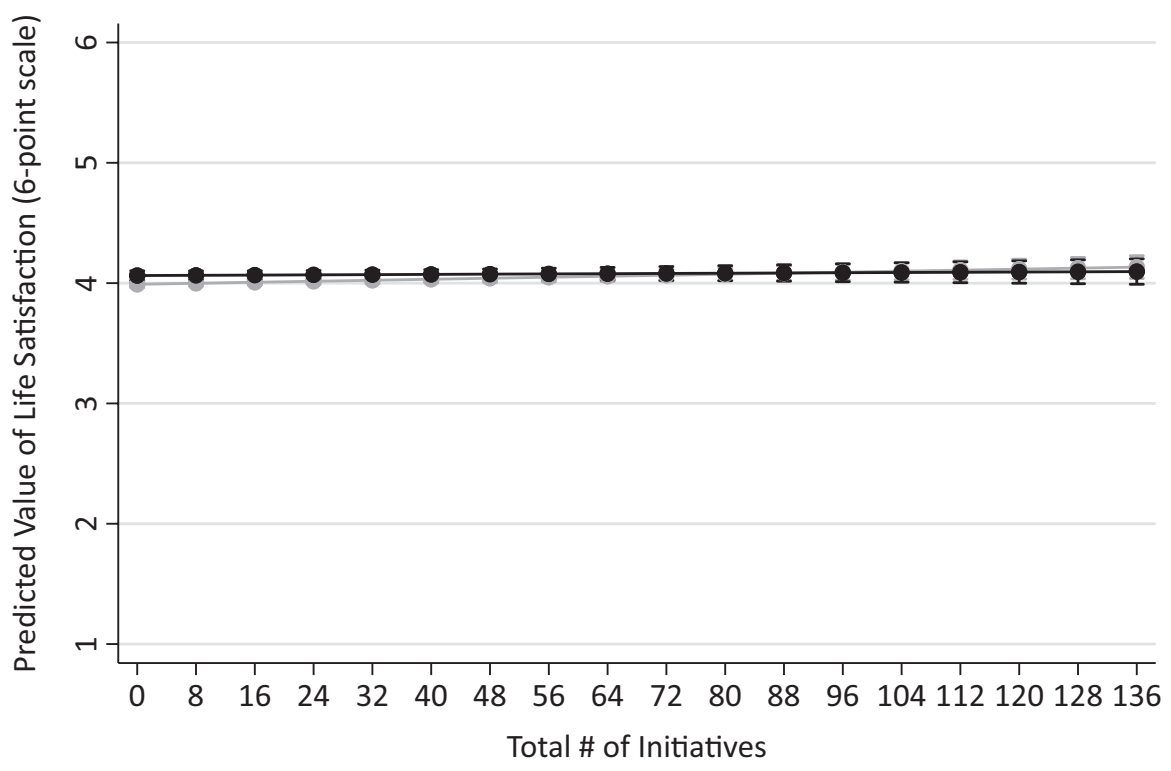

$\longrightarrow$ under $\$ 10,000 \longrightarrow \$ 100,000$ or more

Figure $\mathbf{A} 7 \mathbf{b}$. Figure $A 7$ a, with the $\mathrm{Y}$-axis rescaled to represent the full range of plausible values. 


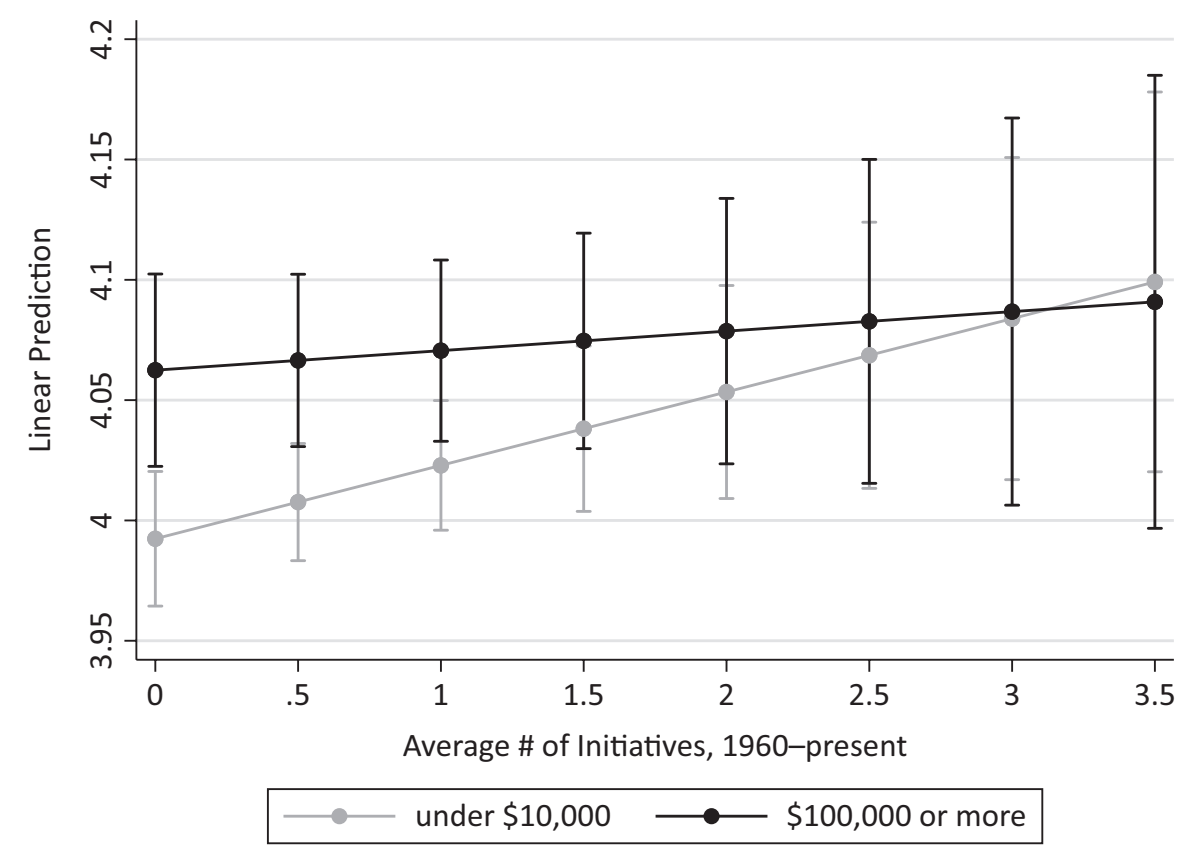

Figure A8a. Interaction of initiative and income, from Table A1 (c).

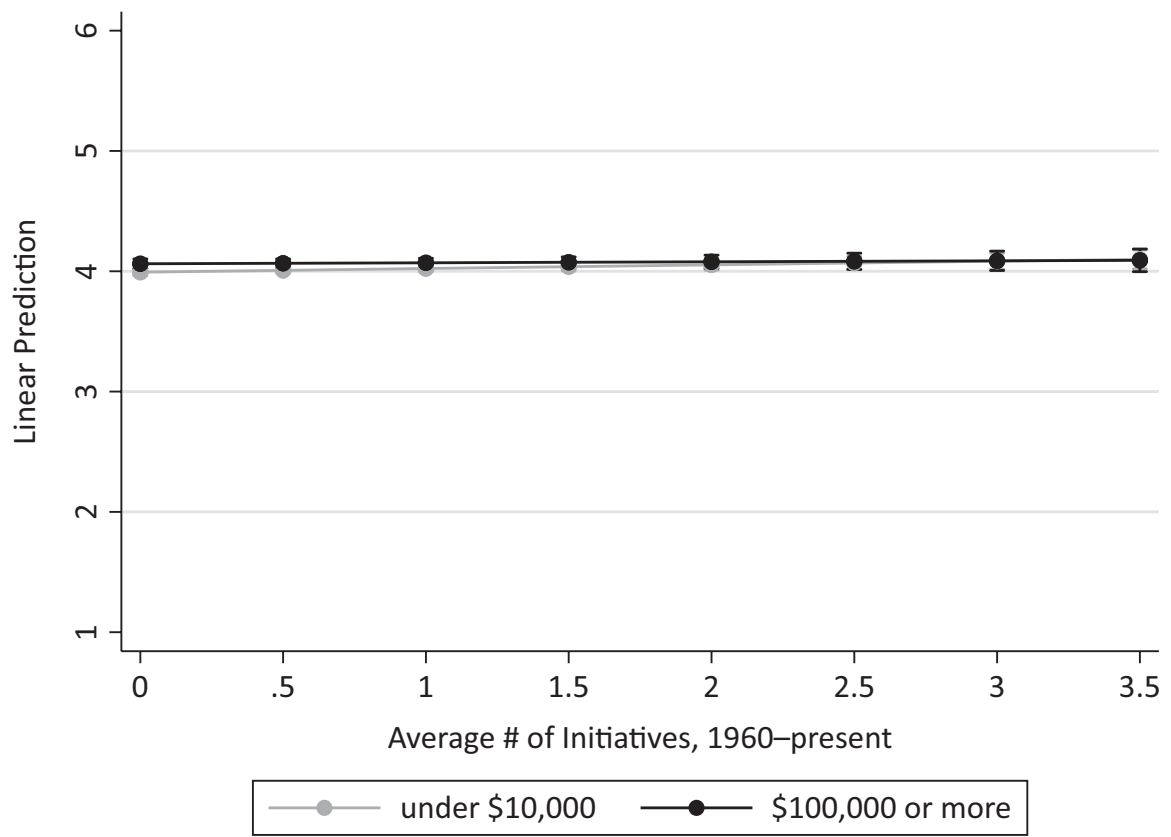

Figure A8b. Figure $A 8$ a, with the $\mathrm{Y}$-axis rescaled to represent the full range of plausible values. 


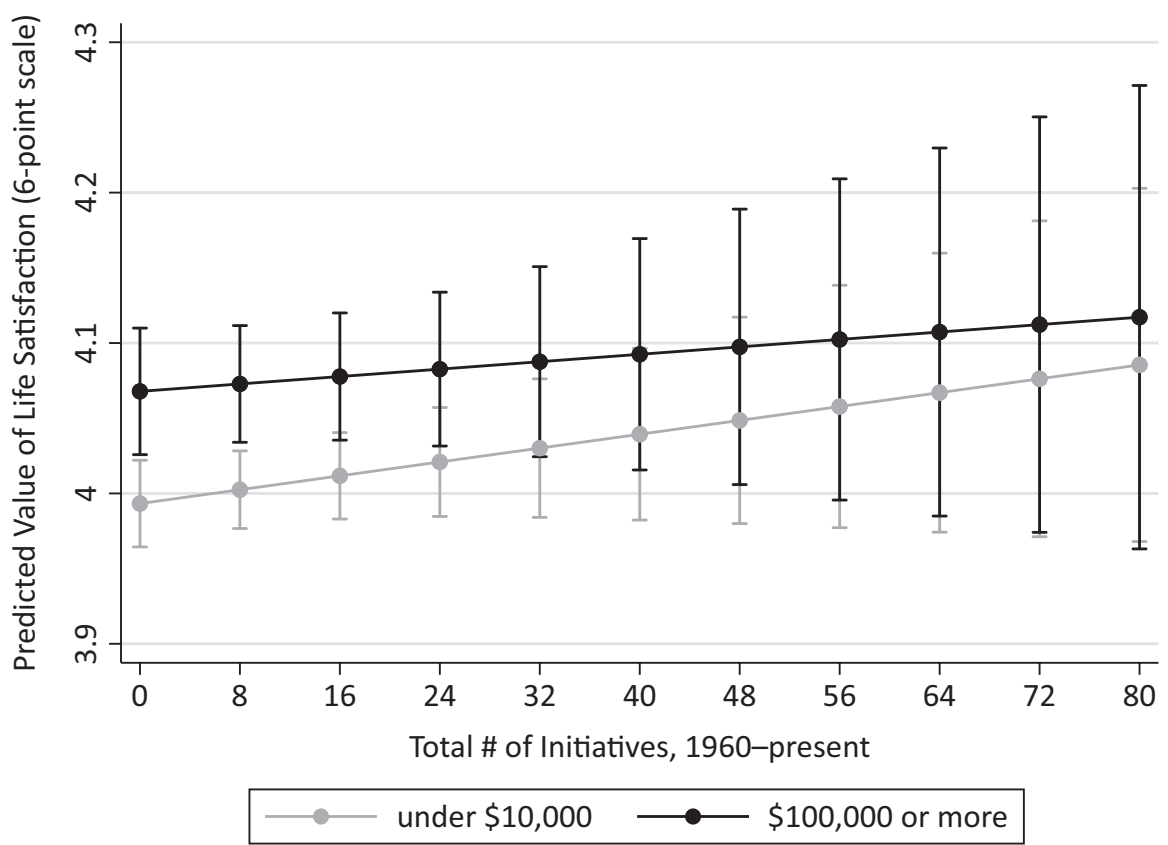

Figure A9a. Interaction of initiative and income, from Table A1 (e).

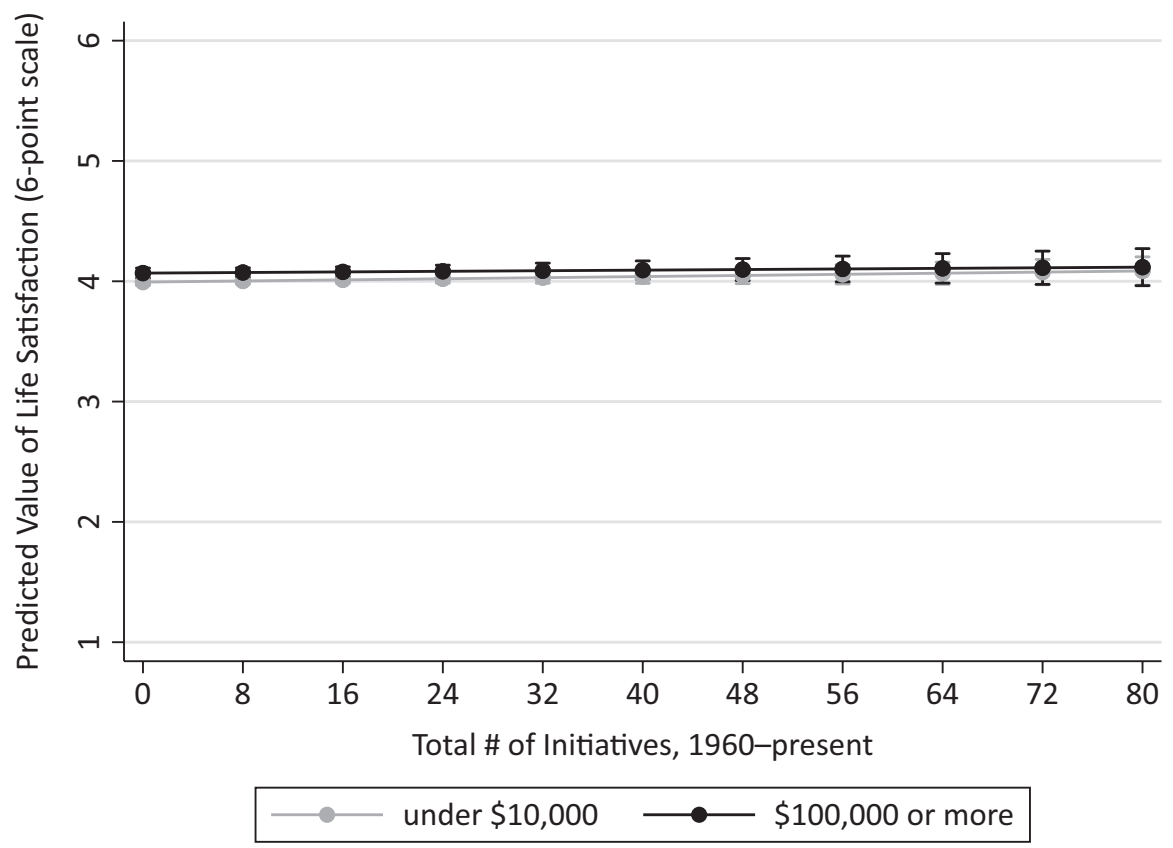

Figure A9b. Figure A9a, with the $\mathrm{Y}$-axis rescaled to represent the full range of plausible values. 


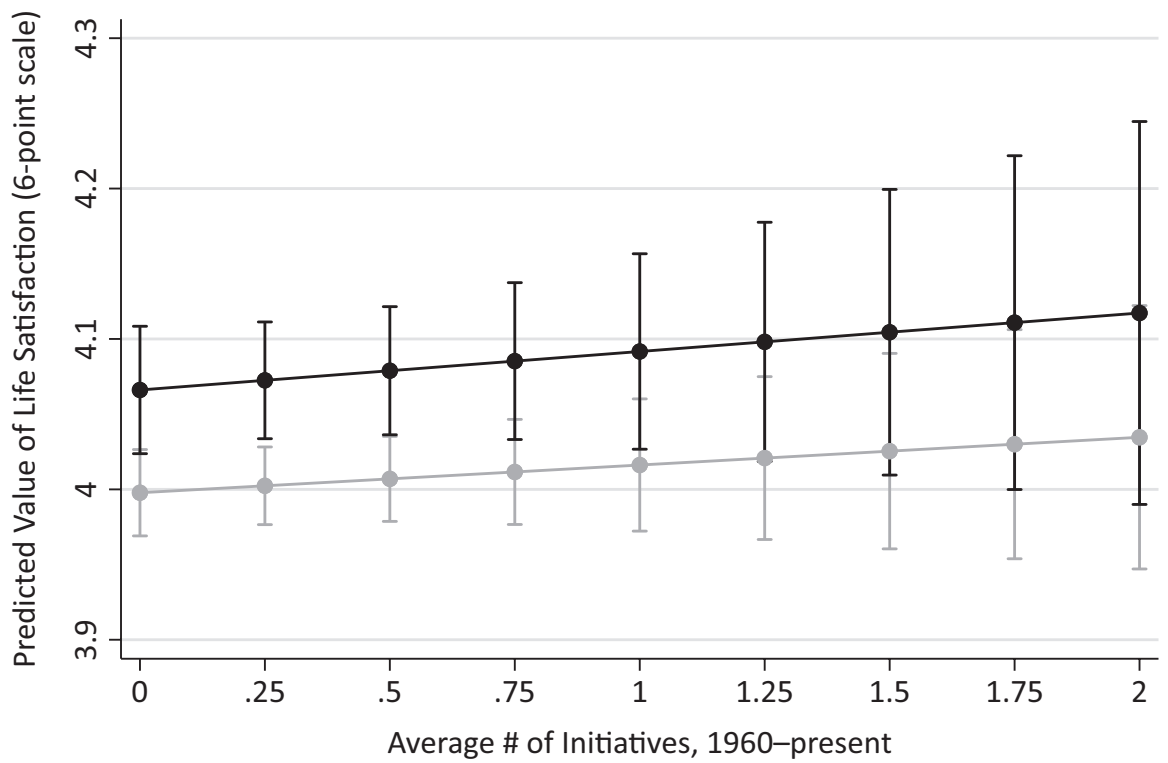

$\longrightarrow$ under $\$ 10,000 \longrightarrow \$ 100,000$ or more

Figure A10a. Interaction of initiative and income, from Table A1 (f).

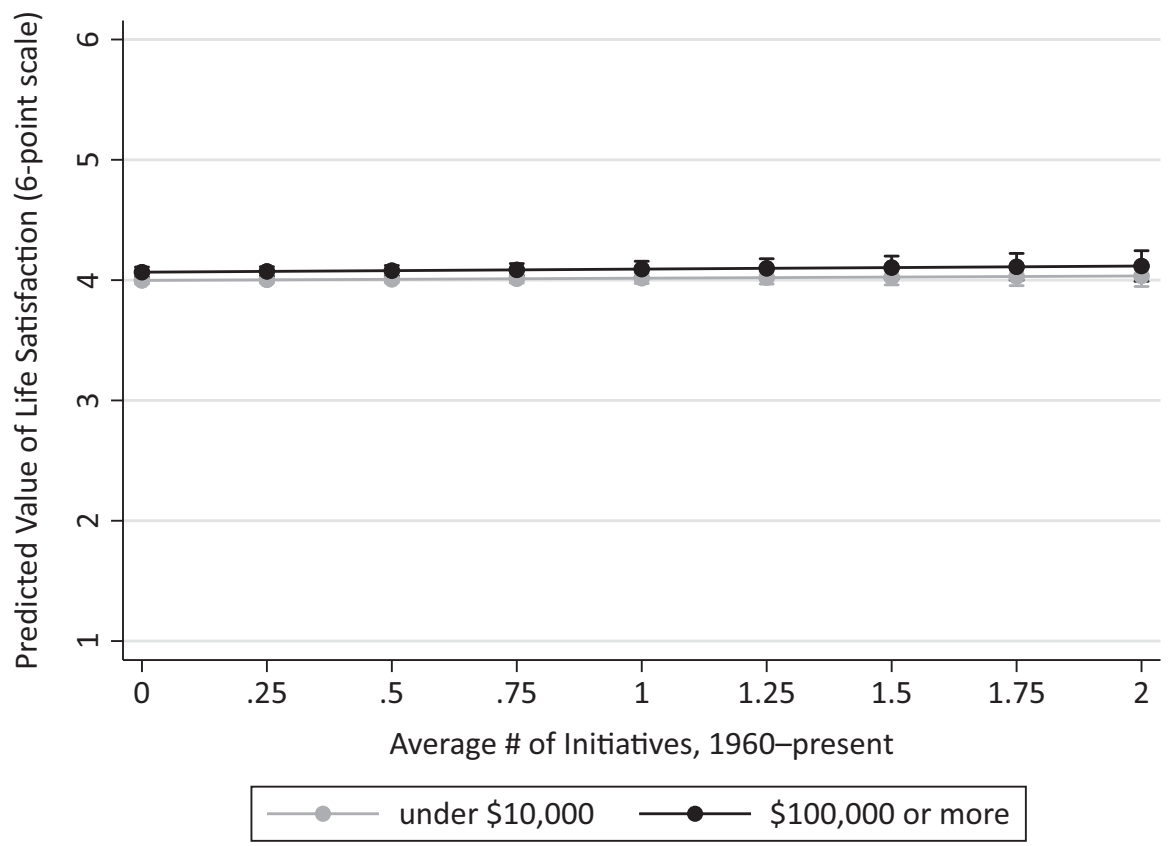

Figure A10b. Figure A10a, with the Y-axis rescaled to represent the full range of plausible values. 


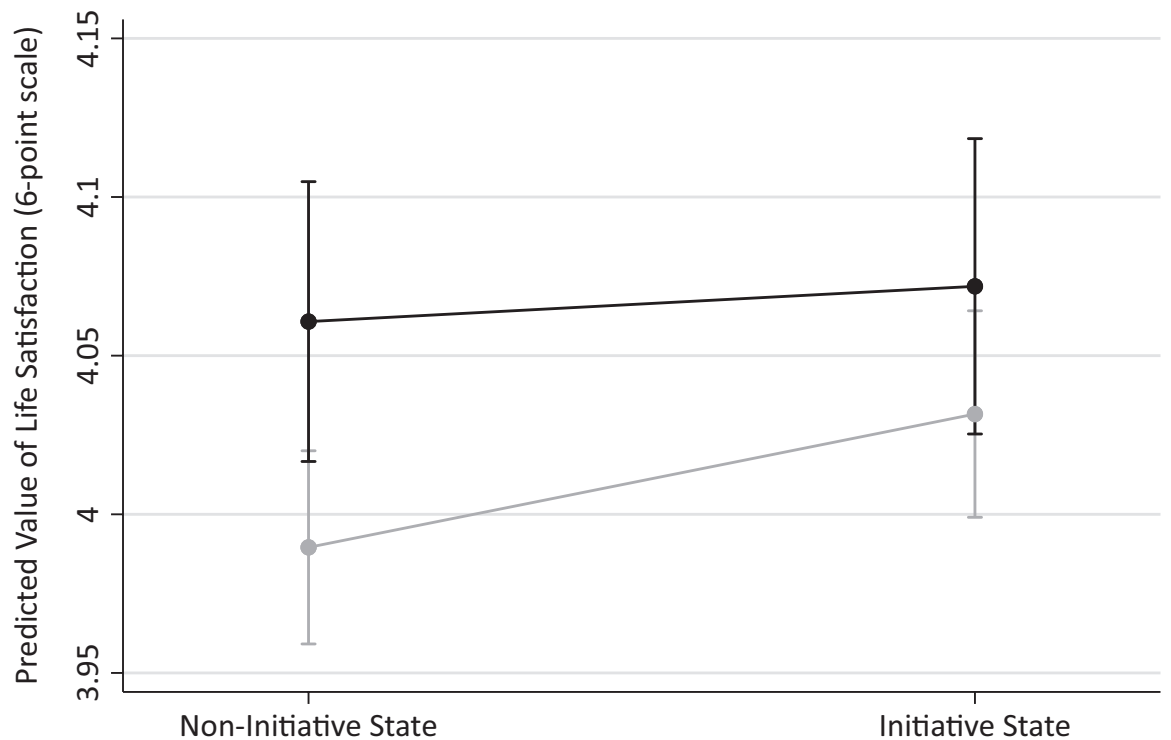

$$
\longrightarrow \text { under } \$ 10,000 \longrightarrow \$ 100,000 \text { or more }
$$

Figure A11a. Interaction of initiative and income, from Table A1 (h).

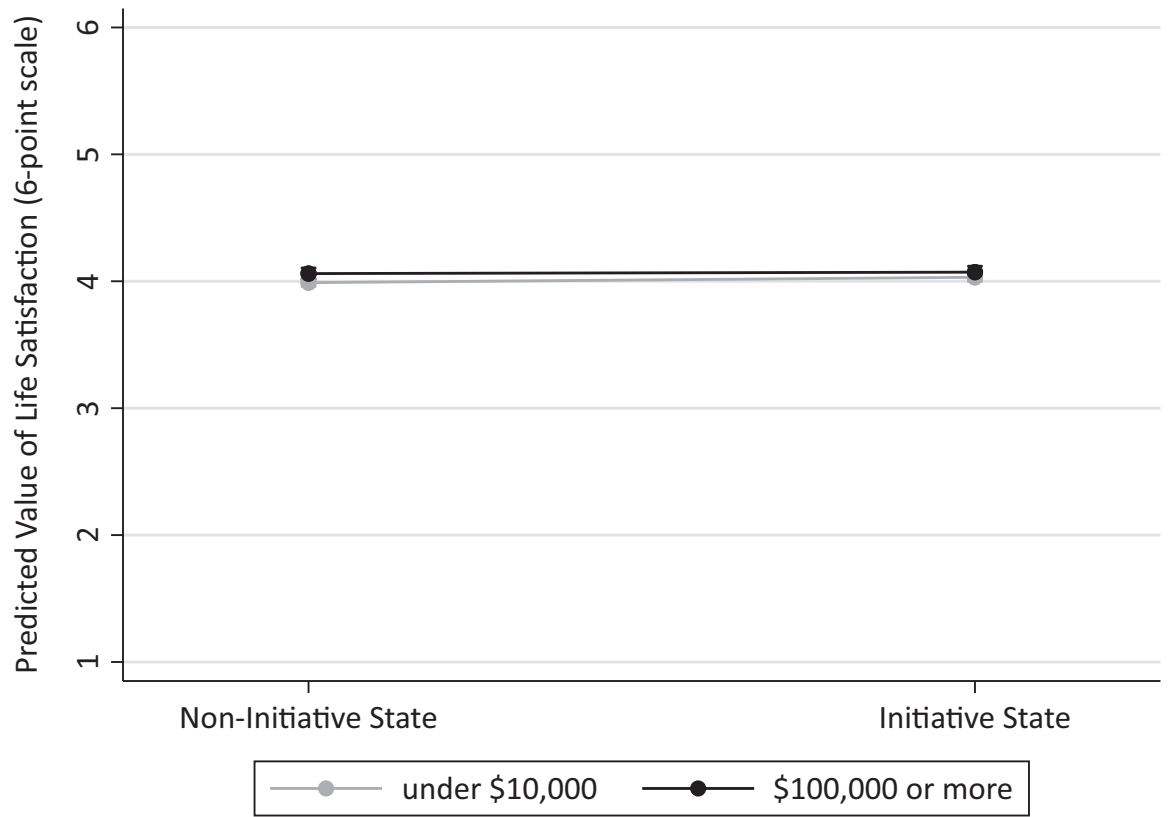

Figure A11b. Figure A11a, with the Y-axis rescaled to represent the full range of plausible values. 


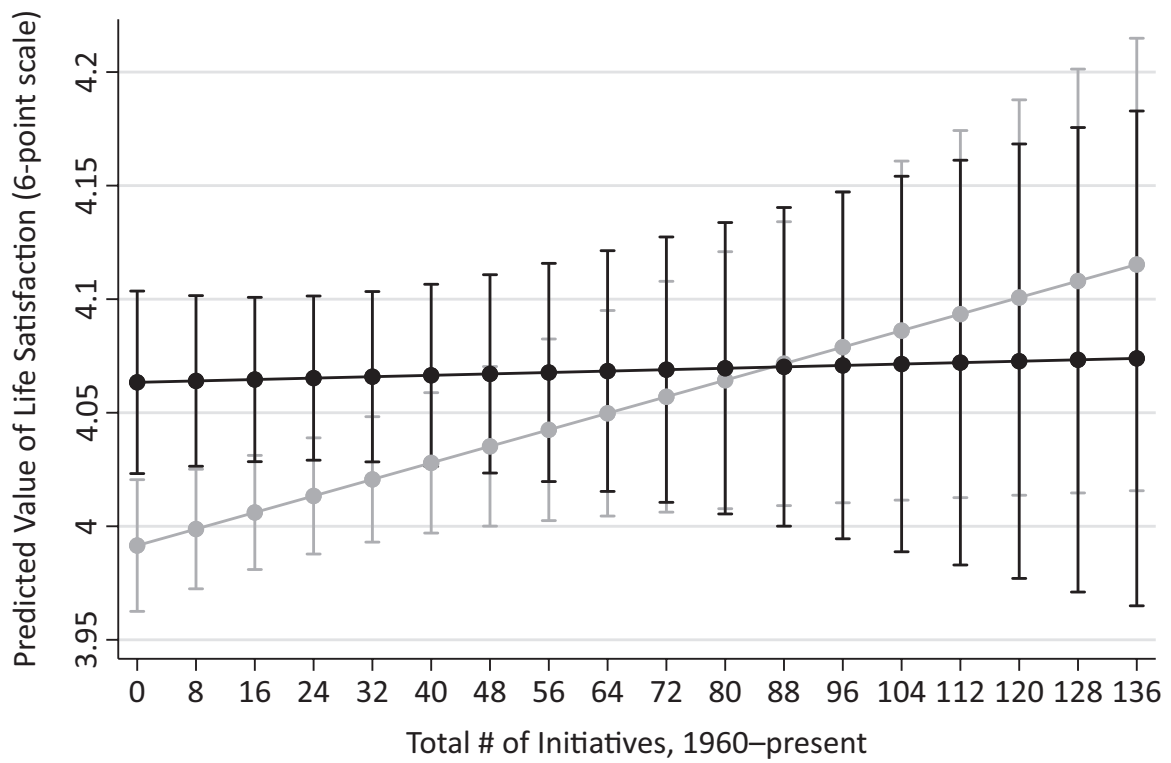

$\longrightarrow$ under $\$ 10,000 \longrightarrow \$ 100,000$ or more

Figure A12a. Interaction of initiative and income, from Table A2 (b).

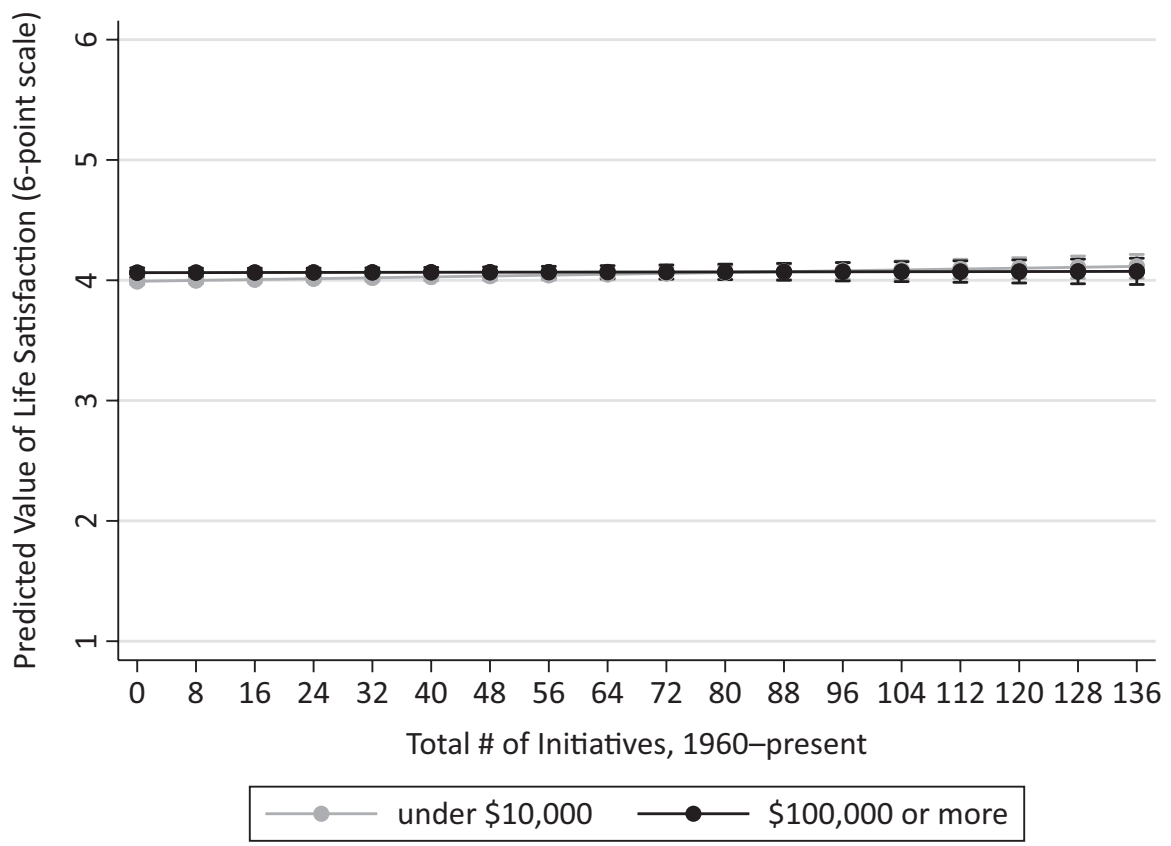

Figure A12b. Figure A12a, with the Y-axis rescaled to represent the full range of plausible values. 


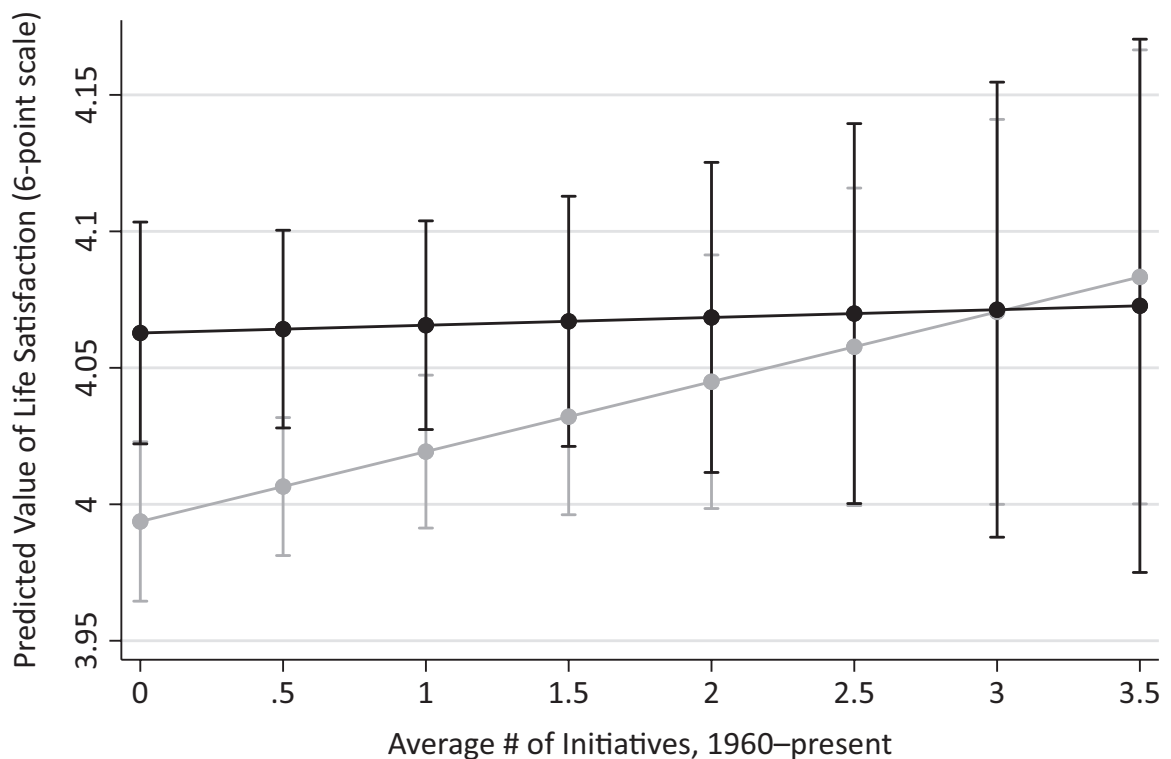

$\longrightarrow$ under $\$ 10,000 \longrightarrow \$ 100,000$ or more

Figure A13a. Interaction of initiative and income, from Table A2 (c).

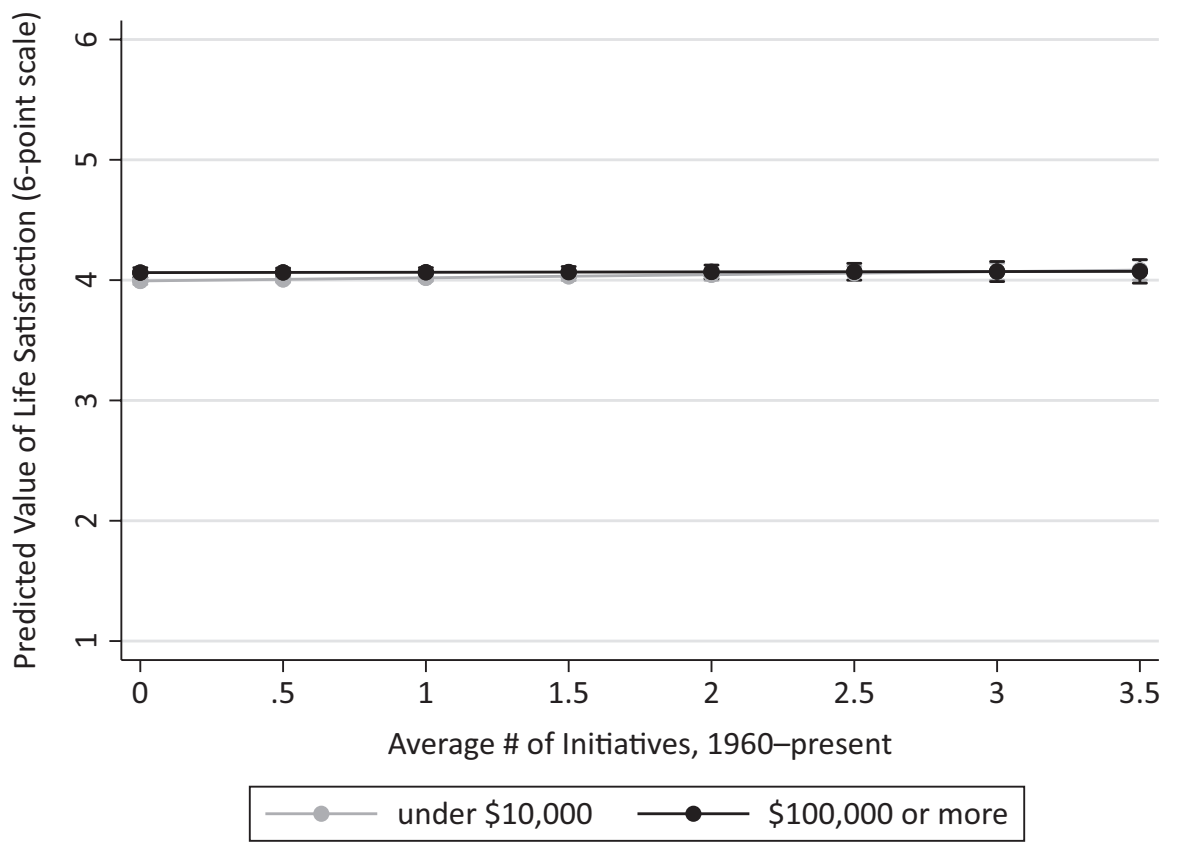

Figure A13b. Figure A13a, with the Y-axis rescaled to represent the full range of plausible values. 

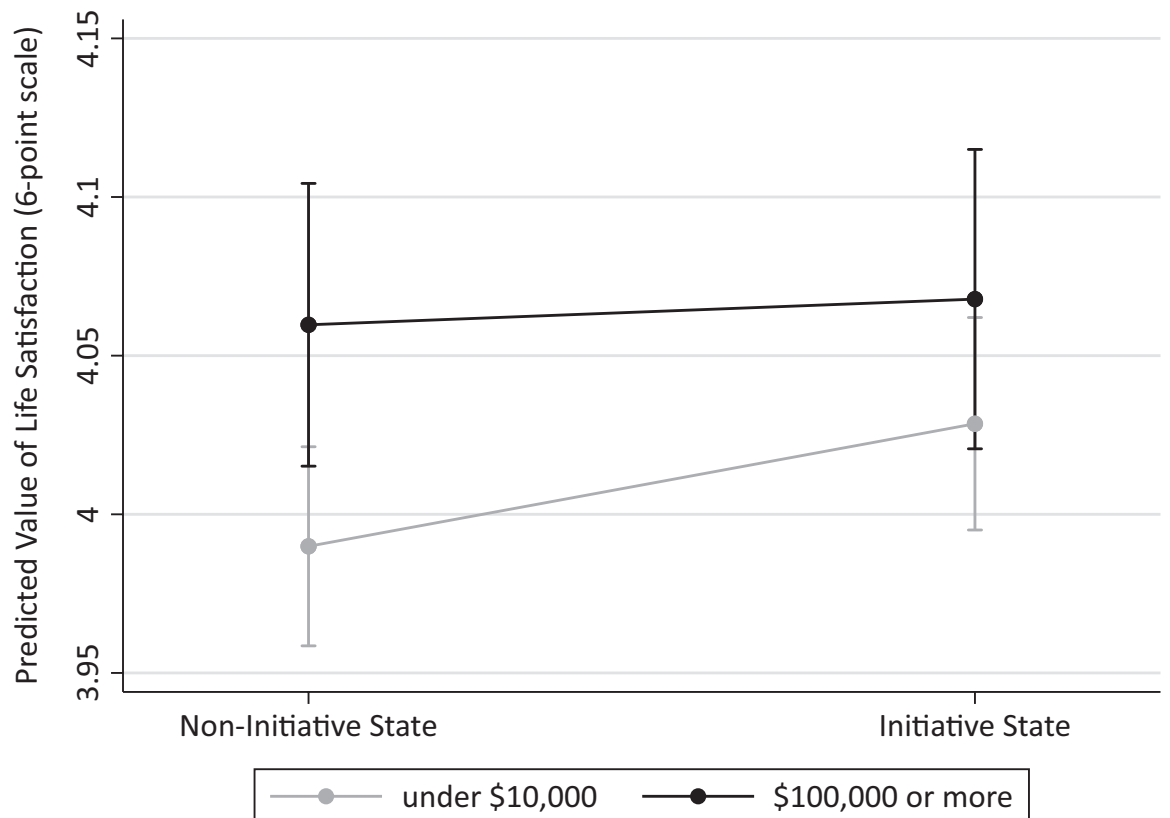

Figure A14a. Interaction of initiative and income, from Table A2 (e).

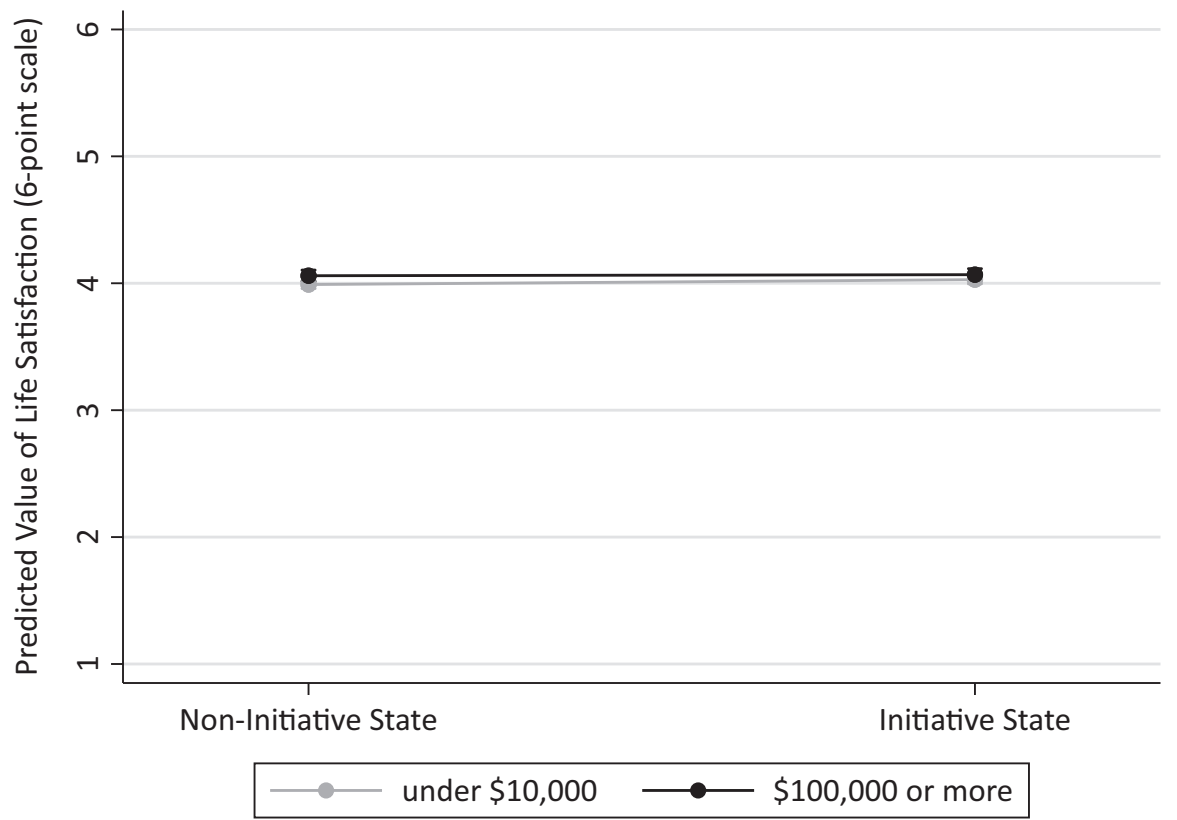

Figure A14b. Figure A14a, with the Y-axis rescaled to represent the full range of plausible values.

The figures also tell a relatively consistent story. Under some specifications, we observe a positive relationship between the ballot initiative and life satisfaction among those with the lowest incomes, but the substantive nature of this effect is small, the slope of this effect is never statistically different than the effect for other income categories, and under other specifications, the sign on the effect goes in the other direction. We do not think that anything about the nature of direct democracy, income, and life satisfaction can be concluded from the DDB Life Satisfaction data presented by R\&S.

In an effort to be fully exhaustive, we also present a series of models in Table A3 that attempt to address some additional modeling issues in R\&S. These include:

- Replacing the measure of diversity with a time-varying covariant. We use the Census State Intercensal Yearly Estimates for 1985-1989 and 1991-1998 and the actual Census data for racial diversity for 1990.

- Adding a control for the liberalism of the state government. The logic here is that a citizen's life satisfaction may be impacted by who controls the government. Here we use the Berry, Ringquist, Fording and Hanson (1998) measure of 
state government ideology. Updated measures are available for download here: https://rcfording.wordpress.com/ state-ideology-data

- We also include a measure of state legislative professionalism as computed by Squire (2007). States with more professionalized legislatures tend to produce better outcomes for their citizens, so it stands to reason that this could increase life satisfaction.

Table A3. Initiatives, income and life satisfaction, an extension.

\begin{tabular}{|c|c|c|c|c|c|c|}
\hline & \multicolumn{2}{|c|}{$\begin{array}{l}\text { Regression with } \\
\text { random effects (a) }\end{array}$} & \multicolumn{2}{|c|}{$\begin{array}{l}\text { Regression with year and } \\
\text { region dummies (b) }\end{array}$} & \multicolumn{2}{|c|}{$\begin{array}{c}\text { 3-level multilevel model, } \\
\text { individuals in state-years } \\
\text { in states (c) }\end{array}$} \\
\hline & Coef & SE & Coef & SE & Coef & SE \\
\hline Initiative Density & 0.027 & $0.015^{+}$ & -0.007 & 0.014 & 0.025 & $0.015^{+}$ \\
\hline Individual Income & 0.005 & $0.002^{* *}$ & 0.005 & $0.002 * * *$ & 0.004 & $0.002^{* *}$ \\
\hline Initiative X Income & -0.002 & 0.002 & -0.002 & 0.001 & -0.002 & 0.002 \\
\hline \multicolumn{7}{|l|}{ State Level Vars } \\
\hline State Population & 0.000 & $0.000^{+}$ & 0.000 & 0.000 & 0.000 & 0.000 \\
\hline State Income (PC) & 0.000 & $0.000^{+}$ & 0.000 & 0.000 & 0.000 & $0.000^{+}$ \\
\hline Racial Diversity & 0.127 & 0.091 & 0.122 & 0.111 & 0.119 & 0.095 \\
\hline Social Capital & 0.000 & 0.015 & 0.017 & 0.021 & 0.001 & 0.016 \\
\hline State Gov't Liberalism & 0.000 & 0.000 & 0.000 & 0.000 & 0.000 & 0.000 \\
\hline Leg Professionalism & -0.006 & 0.058 & 0.043 & 0.070 & -0.003 & 0.060 \\
\hline \multicolumn{7}{|l|}{ Ind'I Level Vars } \\
\hline Financial Satisfaction & 0.394 & $0.004 * * *$ & 0.394 & $0.005^{* * *}$ & 0.395 & $0.004 * * *$ \\
\hline Education & -0.019 & $0.005^{* * *}$ & -0.019 & $0.005^{* * *}$ & -0.019 & $0.005^{* * *}$ \\
\hline Unemployed $(0,1)$ & -0.314 & $0.035^{* * *}$ & -0.312 & $0.043 * * *$ & -0.314 & $0.035^{* * *}$ \\
\hline Sex & 0.087 & $0.012 * * *$ & 0.087 & $0.013 * * *$ & 0.087 & $0.012 * * *$ \\
\hline Children & -0.108 & $0.013^{* * *}$ & -0.109 & $0.015^{* * *}$ & -0.108 & $0.013^{* * *}$ \\
\hline Black & -0.199 & $0.025^{* * *}$ & -0.197 & $0.031 * * *$ & -0.200 & $0.025^{* * *}$ \\
\hline Race-Other & -0.001 & 0.028 & 0.002 & 0.015 & -0.002 & 0.028 \\
\hline Age & -0.042 & $0.002 * * *$ & -0.042 & $0.003 * * *$ & -0.042 & $0.002^{* * *}$ \\
\hline $\mathrm{Age}^{2}$ & 0.000 & $0.000 * * *$ & 0.000 & $0.000 * * *$ & 0.000 & $0.000 * * *$ \\
\hline Widowed & 0.217 & $0.031 * * *$ & 0.215 & $0.038 * * *$ & 0.217 & $0.031 * * *$ \\
\hline Divorced & 0.050 & $0.027^{+}$ & 0.047 & 0.040 & 0.049 & $0.027^{+}$ \\
\hline Married & 0.292 & $0.021^{* * *}$ & 0.291 & $0.029 * * *$ & 0.293 & $0.021 * * *$ \\
\hline Church Attendance & 0.030 & $0.002 * * *$ & 0.030 & $0.003 * * *$ & 0.030 & $0.002 * * *$ \\
\hline Social Trust & 0.106 & $0.005^{* * *}$ & 0.105 & $0.004 * * *$ & 0.106 & $0.005^{* * *}$ \\
\hline Health of R & 0.148 & $0.004^{* * *}$ & 0.148 & $0.005^{* * *}$ & 0.148 & $0.004 * * *$ \\
\hline Year & -0.001 & 0.002 & - & - & - & - \\
\hline \multirow[t]{2}{*}{ Constant } & 4.402 & 3.528 & 2.125 & $0.115^{* * *}$ & 2.134 & $0.083 * * *$ \\
\hline & \multicolumn{2}{|c|}{ Adjusted $R^{2}=.2987$} & \multicolumn{2}{|c|}{ Adjusted $R^{2}=.2988$} & \multicolumn{2}{|c|}{ Residual variance $=1.511$} \\
\hline Intercept variance for state & \multicolumn{2}{|c|}{-} & \multicolumn{2}{|c|}{-} & \multicolumn{2}{|c|}{.0003} \\
\hline Intercept variance for state-years & \multicolumn{2}{|c|}{-} & \multicolumn{2}{|c|}{-} & \multicolumn{2}{|c|}{.0006} \\
\hline Log restricted-likelihood & \multicolumn{2}{|c|}{-} & \multicolumn{2}{|c|}{-} & \multicolumn{2}{|c|}{-77439.7} \\
\hline Wald Test & \multicolumn{2}{|c|}{-} & \multicolumn{2}{|c|}{-} & \multicolumn{2}{|c|}{$20297.2^{* * *}$} \\
\hline $\mathrm{N}$ (states) & \multicolumn{2}{|c|}{48} & \multicolumn{2}{|c|}{48} & \multicolumn{2}{|c|}{48} \\
\hline $\mathrm{N}$ (state years) & \multirow{2}{*}{\multicolumn{2}{|c|}{$\begin{array}{c}672 \\
47636\end{array}$}} & \multicolumn{2}{|c|}{672} & \multicolumn{2}{|c|}{672} \\
\hline $\mathrm{N}$ (individuals) & & & & & & \\
\hline
\end{tabular}

Notes: $+p<.10 ; * * p<.05,{ }^{* * *} p<.01$. Models (a) and (b) are regression models; model (a) includes random effects while model (b) includes fixed effects for state and region (not shown). Model (c) is estimated using a 3-level multilevel mixed linear model: individuals (level 1) in state-years (level 2) in states (level 3).

The addition of these variables does not change the underlying result that the interaction between ballot initiative context and income is not statistically or substantively significant. 


\section{References}

Radcliff, B., \& Shufeldt, G. (2016). Direct democracy and subjective well-being: The initiative and life satisfaction in the American states. Social Indicators Research, 128(3), 1405-1423.

Berry, W. D., Ringquist, E. J., Fording, R. C., \& Hanson, R. L. (1998). Measuring citizen and government ideology in the American states, 1960-93. American Journal of Political Science, 42(1), pp. 327-348.

Squire, P. (2007). Measuring state legislative professionalism: The squire index revisited. State Politics \& Policy Quarterly, $7(2), 211-227$. 